\title{
Bólidos observados y meteoritos caídos en la Península Ibérica durante el siglo XVIII
}

\author{
Enric Aragonès, Carlos Martín Escorza y Jorge Ordaz \\ (Departament de Medi Ambient, Generalitat de Catalunya; \\ Museo Nacional de Ciencias Naturales, CSIC; \\ Departamento de Geología, Universidad de Oviedo)
}

\section{Resumen}

Se presenta un catálogo de los fenómenos meteoríticos observados en la Península Ibérica a lo largo del siglo XVIII. Para ello se ha efectuado un acopio de información publicada e inédita; tras estudiar 33 casos reales o supuestos, se ha confeccionado un catálogo con tres caídas y diez bólidos debidamente contrastados y/o verosímiles. Los resultados presentan un cierto sesgo territorial en razón de la heterogeneidad de los datos de partida; en cuanto a la distribución temporal de los eventos presenta dos máximos: uno en la década de los cincuenta y otro en las dos finales del siglo, los cuales se correlacionan bien con los datos disponibles a nivel global. Por otra parte, se ha estudiado la historia terrestre de los meteoritos, así como la evolución de la interpretación de tales fenómenos con el tiempo, desde las conjeturas pre-científicas a la aceptación de su origen extra-terrestre.

\section{Palabras clave}

Meteoritos. Bólidos. Siglo XviII. España. Portugal.

CES.XVIII, núm. 16 (2006), págs. 5-50. 


\section{Introducción}

Hasta fechas relativamente recientes, la humanidad ha presenciado con sorpresa y aprensión las ocasionales apariciones de señales de fuego en el cielo, así como de la caída de piedras meteóricas. El desconocimiento de la verdadera naturaleza de tales fenómenos hizo que desde un principio se les asociara a causas fabulosas o sobrenaturales, favoreciendo las creencias de carácter sagrado y la proliferación de ambivalentes presagios y vaticinios.

Un halo de misterio y superstición comparable al que suscitaba el paso de cometas ha rodeado desde antiguo a los llamados «globos de fuego», meteoros ígneos de origen diverso entre los que se cuentan los bólidos producidos por la entrada en la atmósfera de piedras meteóricas, abundantemente documentados a partir del siglo Xv, y sobre cuya procedencia y características se hicieron hipótesis de todo tipo durante la segunda mitad del XVIII ${ }^{1}$.

Por otro lado, las piedras caídas del cielo se asociaron desde la antigüedad a los rayos y truenos, por el parecido de las manifestaciones visuales y acústicas que acompañan su caída con dichos meteoros atmosféricos, dando origen a la creencia de que los rayos acarreaban materia sólida (Telum); de donde se pasó a asociar ciertos tipos de piedra al rayo. Creencia que ha quedado fijada en distintos idiomas: donnerstein, thunderstones, pierres de tonnerre, piedras de rayo, pedres de llamp, etc. Véase este párrafo escrito por un erudito español del seiscientos:

Otras veces el rayo es piedra que se quaja de vapor y exhalacion terrestre mineral en alguna nuve verde o negra cocida allí con la virtud del fuego y influencias; endurecida y rompida la nube cae impetuosamente. Rompe las piedras, paredes: y derriba los edificios fuertes y muros².

A pesar del gran impacto que causó entre los intelectuales centroeuropeos la famosa caída de Ensisheim (Alsacia), ocurrida el 7 de noviembre de $1492^{3}$, los primeros intentos de explicar los fenómenos meteoríticos mediante causas

1 Véase, por ejemplo, F. HeIDE \& F. WLOTZKa, Meteorites: Messengers from Space, Springer-Verlag, 1995; O. R. Norton, Rocks from Space, Mountain Press Publ. Co., 1998; y H. Y. McSweEn Jr., Meteorites and Their Parent Planets, Cambridge University Press, 1999.

2 B. Pérez de Vargas, Fábrica del Universo, Toledo, Ayala, 1663.

3 El célebre Alberto Durero [1471-1528] debió de ser testigo presencial de esa caída: en una pintura descubierta en 1960 al dorso de su Penitencia de San Jerónimo (1494) representó ese acontecimiento; su recuerdo parece que le acompañó siempre, pues en 1514 en su Melancolía, dibuja en el cielo un gran bólido. Durante el XvIII el origen de ese célebre meteorito fue objeto de una discusión en la que intervinieron Goethe — quien tuvo ocasión de verlo en 1771—, Chladni y Lavoisier (U. B. Marvin, «The meteorite of Ensisheim: 1492 to 1992», Meteoritics, 27, 1992, págs. 28-72). 
físicas no se produjeron hasta los tiempos de la Ilustración, tres siglos después: se propusieron entonces diversas y variopintas hipótesis genéticas, una de las cuales, la del origen extra-terrestre enunciada por Chladni en 1794 tras estudiar las masas de hierro encontradas en Siberia y otros puntos, se acabó imponiendo con el tiempo, aunque no sin dificultades ${ }^{4}$.

Algunas caídas espectaculares registradas en Inglaterra, Francia e Italia a finales del XVIII y principios del XIX suscitaron gran atención, apareciendo entonces los primeros tratados de la materia, los intentos de catalogación, los primeros estudios analíticos de las piezas y la formación de colecciones. En general los catálogos suelen limitarse solamente a las caídas meteóricas; sin embargo en 1861 Greg realizó el meritorio intento de reunir en uno solo a bólidos y meteoritos.

En España el primer tratado sobre la materia aparece en 1854 con la firma de Joaquín Balcells. Hacia 1880 el marqués del Socorro organiza la colección del Museo de Ciencias de Madrid a base de piezas existentes y de intercambios con otros museos; colección que fue considerablemente aumentada por Calderón y Fernández Navarro durante el primer tercio del siglo xx. El primer catálogo razonado de los meteoritos caídos en la Península Ibérica se debe a Marià Faura i Sans: se publicó en 1922 y bien puede decirse que no ha sido superado por la cantidad de información que aporta de los meteoritos conservados en su época. Faura incluye además algunas observaciones de bólidos, si bien omitiendo muchas de las relacionadas por Greg, cuyo catálogo le pasó inadvertido ${ }^{5}$. Martín Escorza añade dos caídas supuestamente ocurridas en Los Rábanos (Soria) ${ }^{6}$.

No es mucha la información existente sobre los fenómenos meteoríticos peninsulares del siglo XVIII: $\mathrm{Greg}^{7}$ documenta tres caídas y tres bólidos de

4 En 1794 Ernst Florens Friedrich Chladni [1756-1827] dio a conocer su hipótesis en el artículo, escrito en alemán, «Sobre el origen de las masas de hierro encontradas por Pallas, y otras similares a ella, y sobre algunos fenómenos naturales con ellas relacionados», obra considerada hoy como el texto fundacional de la ciencia meteorítica. Unos años antes (1788), el capitán de fragata Miguel Rubín de Celis había descrito, en el vol. 78 de las Philosophical Transactions of the Royal Society of London, la «masa de fierro» encontrada en la región del Chaco Austral (actual Campo del Cielo, Argentina), aunque sin llegar a relacionarla con los globos de fuego. Véase, sobre Chladni y el nacimiento de la ciencia de los meteoritos, U. B. MArvin, «Ernst Florens Friedrich Chladni (1756-1827) and the origins of modern meteorite research», Meteoritics \& Planetary Science, 31 (1996), págs. 545-588. Una edición actual de su texto fundamental puede encontrarse en el comercio bajo el título Über den kosmischen Ursprung der Meteorite und Feuerkugeln (Thun, H. Deutsch, col. «Ostwalds Klassiker der Exakten Wissenschaften», vol. 258).

5 M. Faura y Sans, Meteoritos caídos en la Península Ibérica, Revista semanal Ibérica, Extr. de Ibérica, núms. 17 (1922): págs. 154-157; 202-208; 314-318; y 18: 25-31; 123-126; 137-139; 234-238; 362-364.

6 C. MarTín Escorza, «Fenómenos meteoríticos ocurridos en España», Boletín de la Institución Libre de Enseñanza, 3 (1987), págs. 51-68.

7 R. P. GREG, «A catalogue of meteorites and fireballs from AD 2 to AD 1860», Report of the $13^{\text {th }}$ Meeting of the British Association for the Advancement of Science, Oxford, june-july 1860, Londres, Murray, 1861 (página web por E. Hutton). 
dudosa autenticidad; por su parte Faura, en Meteoritos, contempla tan solo dos caídas y un bólido. A diferencia de las tres caídas (Terrassa 1704, Sigena 1773 y Tasquinha 1796), las observaciones de bólidos apenas han sido estudiadas anteriormente. Por otra parte, el siglo de las luces resulta un campo de estudio privilegiado, tanto por la cantidad de documentos existentes como por la evolución de la percepción de tales fenómenos, desde las interpretaciones esotéricas de principios de siglo hasta las hipótesis genéticas más o menos científicas.

Es en este ámbito en el que se ha llevado a efecto el presente trabajo, con el doble objetivo de elaborar un nuevo catálogo de observaciones y de estudiar la evolución de la percepción de los fenómenos. Para ello se ha efectuado una recopilación, lo más exhaustiva posible en el momento presente, de las noticias de observaciones de fenómenos de presumible origen meteorítico; tras una primera valoración de cada una de ellas, se ha confeccionado un catálogo con las noticias verosímiles, contrastadas o fiables, descartando todas las demás. Se ha valorado la representatividad del catálogo así obtenido, poniendo de relieve su sesgo así espacial como temporal. Por último, se ha seguido la evolución de la interpretación de los fenómenos meteoríticos a lo largo del tiempo.

\section{Relación de Observaciones}

1700, 14 de noviembre. Supuesto bólido observado en El Torn (Gerona)

Una hora antes del día apareció una gran estrella llameante, y otra en el mismo día por la noche; fue cosa muy maravillosa, pues parecía ser de díå.

Muy dudoso; la repetición parece remitir a otra clase de fenómenos.

1701, 6 de abril. Supuesto bólido visto en Barcelona, a las 22 horas

En los Anales de Cataluña se lee que ese día se manifestó a las 22 horas un globo de fuego con una larga cola muy resplandeciente que salió de la parte de oriente y se encaminó a occidente, pasando entre el convento de la Merced y

8 Anotación en el Llibre de baptismes de 1700 de la parroquia de Sant Andreu del Torn; citada en Ll. Constans, «Una crónica inédita de la Guerra de Sucesión en Gerona», Anales del Instituto de Estudios Gerundenses, 5 (1950), págs. 73-112. 
Montjuïc; duró cosa de dos credos y daba tanta claridad que parecía ser de día. Añadieron los pescadores que lo vieron que pasada Barcelona se dividió en dos con gran estruendo; cayeron algunas luces y se percibieron algunos estallidos 9 .

Dudoso: la duración parece excesiva para un bólido. Greg lo consignó en el suplemento a su catálogo de 1861, probablemente a partir de la fuente que se indica.

\section{Bólido observado en Valencia}

Refiere el doctor Tosca que ese año se vio en Valencia y otras partes un meteoro muy resplandeciente de los llamados Llama y Antorcha, que duró brevísimo tiempo; con magnitud extraordinaria ${ }^{10}$.

Se trata verosímilmente de un bólido, notificado por uno de los principales físicos de la época. No se descarta que fuera el mismo observado en Barcelona, pero por desgracia el autor no concreta la fecha ni la hora del evento.

\section{4, 3 de abril. Supuesto bólido observado en Barcelona, a las 14 horas}

A las 2 de la tarde se observó un globo de fuego, juzgándole unos al mediodía, otros hacia Montserrat; se dividió con tal estruendo como si disparase la artillería y la mosquetería; corrieron noticias escritas ${ }^{11}$.

Muy dudoso: tanto sus características como la circulación de la noticia en los papeles remiten al meteoro de 25 de diciembre.

1704, 4 de octubre. Supuesto bólido observado en Barcelona

Se vio caer un bólido en la bahía (i) de Barcelona ${ }^{12}$.

\footnotetext{
9 «Vision en el ayre», en N. FeLIu DE LA PeÑa, Anales de Cataluña y epílogo breve de los progressos, y famosos hechos de la nacion Catalana, de sus Santos, Reliquias, Conventos y singulares Grandezas, y de los mas señalados, y Eminentes Varones, que en Santidad, Armas, y Letras han florecido desde la primera Poblacion de España Año del Mundo 1788. antes del nacimiento de Christo 2174. y del Diluvio 143. hasta el presente de 1709. Barcelona, J. P. Martí, 1709, 3 vols., t. 3, pág. 475.

10 T. V. Tosca, «Tratado XXII Phisico-Mathematico de los Metheoros terrestres, aqueos, aereos, y ethereos», Compendio Mathematico en que se contienen todas las materias mas principales de las Ciencias que tratan de la Cantidad, Valencia, V. Cabrera, 1713, t. 6, págs. 429-542, la cita en la pág. 508.

11 «Lucido globo de fuego con estruendo en el ayre», en FeLIU DE LA PeÑa, 1709, vol. 3, pág. 517; F. Castellví, Narraciones históricas desde el año 1700 hasta el año 1725 [1733-1737], Madrid, Fundación F. Elías de Tejada y E. Pércopo, 1997-2000, 3 vols., vol. 1, pág. 465.

12 Así, sin otra indicación, en el catálogo de R. P. GREG, «A catalogue of meteorites and fireballs from AD 2 to AD 1860».
} 
Muy dudoso. Se desconoce la fuente primaria de esta noticia.

1704, 25 de diciembre. Meteorito caído en Terrassa a las 17 horas

A las cinco de la tarde del día de Navidad de 1704 se observó, en gran parte de Cataluña y muy especialmente desde Barcelona, una espectacular «señal de fuego» cruzando el cielo. Tras explotar y desintegrarse, cayó una lluvia de piedras, siendo recuperadas algunas de ellas cerca de Terrassa.

El fenómeno, por su aparatosidad, fue recogido en dietarios oficiales y privados manuscritos, en impresos varios (figura 1), así como en crónicas y recopilaciones históricas setecentistas y ochocentistas ${ }^{13}$. Probablemente se debe a la difusión de los Anales de Cataluña de Narcís Feliu de la Peña (1709) su inclusión como «Barcelona» en los catálogos meteoríticos de Chladni y Greg.

En 1921, Faura i Sans lo redescubrió para los catálogos ibéricos ${ }^{14}$; para Martín Escorza se trata de una «caída», pero Martínez Frías se refiere a ella como «dudosa» ${ }^{15}$. En Grady consta como «caída observada» ${ }^{16}$. Muñoz-Espadas ${ }^{17}$ lo incluye en la categoría de «meteoritos no localizados». Recientemente ha sido objeto de diversos estudios y trabajos de divulgación.

Bólido. El paso del bólido fue observado, por lo menos, desde Barcelona, Matadepera, Santa Susana, Verges, y El Collell. Apareció sobre las cinco de la tarde, estando el cielo sereno y sin nubes. Los testigos lo describieron como «globo», «viga» o «barra» de fuego, «exhalación» o «rayo» por su luminosidad muy brillante y resplandeciente. Dejó a su paso un rastro de «humo» en la

13 Véase J. Llorca et al, «The meteorite fall of 1704 at Barcelona», 65th annual Meteoritical Society Meeting, Los Angeles. Meteoritics \& Planetary Science, suplemento al vol. 37, 7 (2002), pág. A89; J. LLORCA, «Les pedres de casa», dins Pedres que cauen del cel. L'impacte dels meteorits en la història de la ciència. Lleida, Pagès ed. (Col. «Argent viu», 61), 2003. Versión castellana: «El meteorito de la guerra de sucesión española», en Meteoritos y cráteres: fragmentos de otros mundos que caen en la Tierra. Madrid, Ed. Milenio, 2004; J. LLORCA, J. «Foc sobre Terrassa», Sàpiens, 17 (2004), págs. 36-39; E. Aragonès, «Senyal de foc al cel (25 de desembre de 1704)», Notícies de Natura, 10 (2005), 10+x págs.

14 M. Faura reproduce el texto del Dietario Municipal de Barcelona, única fuente por él conocida (M. FAURA I SANS, «Meteorits caiguts a Catalunya», Butlletí del Centre Excursionista de Catalunya, 31, n. 322 (1921), págs. 270-288). El mismo autor reproduce en su catálogo de 1922 la noticia; pero en la lista de meteoritos al final del trabajo dice «cayó en el mar» (M. FAura y SANs, Meteoritos caídos en la península Ibérica). En la hoja 35 (Barcelona) del Mapa Geológico de Cataluña a escala 1:100.000, llegó a señalar un punto en el mar donde supuestamente ocurrió la caída. Todavía hoy algunos catálogos como el de la Astronomical Research Network recogen esta especie, que resulta inverosímil, sabiendo que la caída ocurrió en realidad en Terrassa, a $30 \mathrm{~km}$. del mar.

15 Martínez Frías et al., «Los meteoritos», Mundo científico, 9, 93 (1989), págs. 742-749.

16 M. M. Grady, Catalogue of meteorites, Cambridge University Press, 2000 (5. a ed).

17 M. J. Muñoz-Espadas et al., «The meteorite collection of the National Museum of Natural Sciences, Madrid, Spain: An updated Catalog», Meteoritics and Planetary Science, Supplement 37 (2002), págs. B89-B95. 

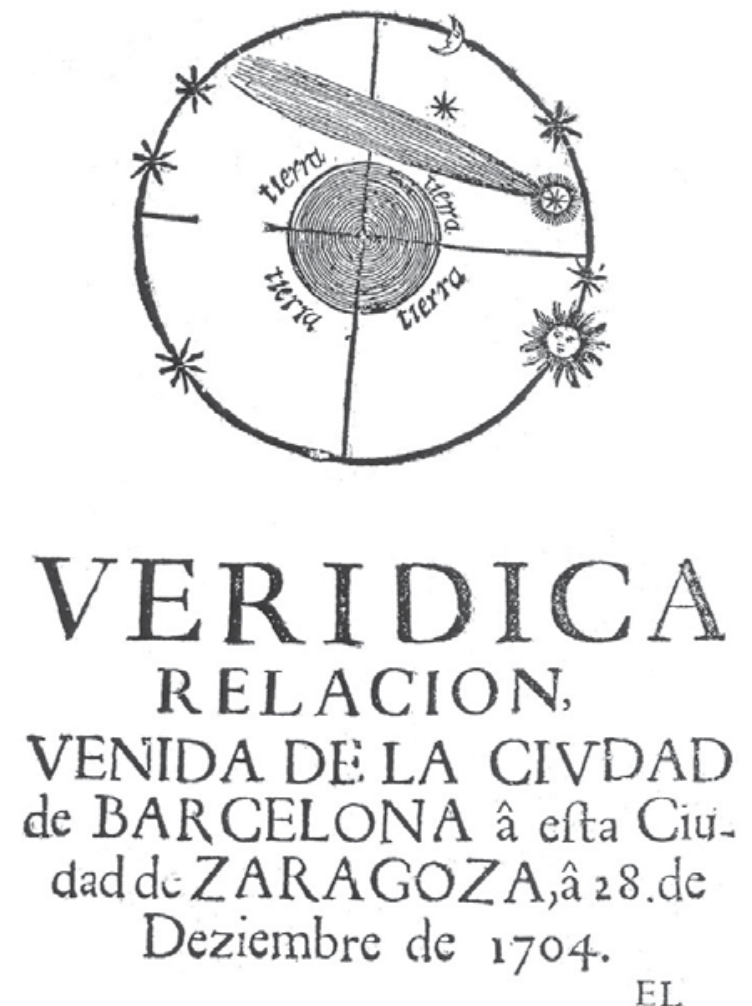

Figura 1. Portada de una hoja impresa en Zaragoza con la noticia del bólido observado en Barcelona el 25 de diciembre de 1704.

atmósfera que permaneció por espacio de una hora antes de desvanecerse. La trayectoria, teniendo en cuenta que se observó a poniente de Barcelona y al sur de Matadepera, debió de ser SSO-NNE ${ }^{18}$ (ver figura 2). Los ruidos que acompañaron su estallido (se dividió en tres partes, según algunos testigos) varían en calidad e intensidad según la distancia del observador: se describieron como «trueno», «estruendo», «rimbombo», descargas de artillería y fusilería, etc.; su duración se estimó entre uno y tres «credos», según las fuentes. Véase la documentación transcrita por Llorca y Aragonès, en especial el relato de Miquel Batlles de Matadepera, testimonio insólito de una observación frontal ${ }^{19}$; o el del abogado barcelonés Mas y Soldevila:

Aparece en el aire una señal de fuego, y se resuelve en un trueno muy fuerte / Por la tarde, poco después de las cinco, apareció en el aire como si estuviera encima de esta ciudad, estando el cielo claro y sereno, sin nube ni bruma alguna, un meteoro

18 Aragonès, «Senyal de foc», figura 2.

19 Llorca, «Les pedres» y Aragonès, «Senyal de foc». 


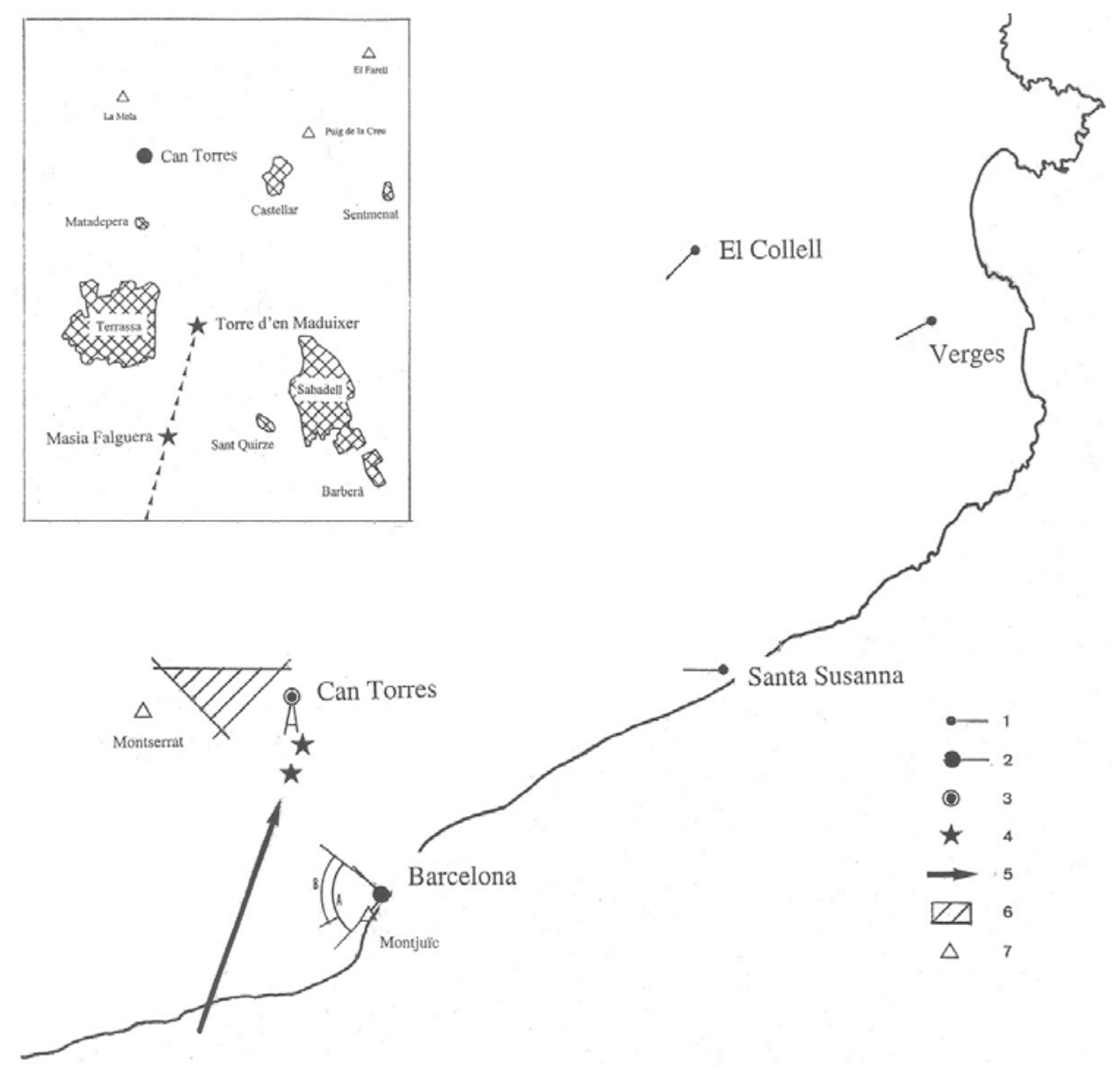

Figura 2. Caída de Terrassa (25/12/1704). Observadores y dirección de observación: 1, lejanos; 2, cercano; 3, frontal; Trayectoria: 4, puntos de caída; 5: Trayectoria deducida; 6, lugar donde se observó el fenómeno, según los observadores lejanos; Observación desde Barcelona: 7, puntos de referencia; A, ángulo de visión definido por los puntos de referencia; B: ángulo de visión deducido de las indicaciones astronómicas de Joan Solar.

hecho a modo de globo de fuego, que por espacio de la cuarta parte de un avemaría lanzó tal resplandor, que siendo mucho mayor que el de un rayo, asustó en gran medida a todos, y apagándose luego se resolvió en una nube, o humo, del cual por espacio de uno o dos credos, se oyó notablemente un trueno como si fuera una carga de mosquetería, lo que asustando como he dicho a la gente, dio a muchos que pensar y discurrir / [nota al margen:] en particular sabiéndose después que en término de Terrassa se advirtió que habían caído algunas piedras sulfúreas a modo de escoria, que pesaban más de una libra; al tiempo que se sentía allí aquel estruendo ${ }^{20}$.

20 De un dietario manuscrito original de Manuel Mas y Soldevila, en la Biblioteca Episcopal de Barcelona; traducido del catalán. Manuel Mas y Soldevila, doctor en derecho y político, perteneció al Consejo 
Meteoritos. Las fuentes no están de acuerdo en el número y peso de las piezas caídas. Según Batlles, cayeron por lo menos dos piedras que pesaron entre 2,5 y 3 libras; Mas y Soldevila asegura que fueron varias y su peso era superior a una libra, y en una nota anónima publicada se lee que fueron 10 o 12 las piedras caídas, algunas de las cuales llegaron a pesar 12 libras $^{21}$. Según Feliu de la Peña eran «piedras grandes de color negro, y dentro de color ceniciento». Para Mas y Soldevila semejaban escoria de fundición; otros testigos hablan de «piedras sulfúreas» $\mathrm{y}$ «como chamuscadas de pólvora».

\section{5, 23 de noviembre. Supuesto bólido observado en Barcelona}

Se califica de «fenomina» y de «confirmación del prodigioso señal que se vio en 25 de Deziembre de $1704 »^{22}$.

Muy dudoso; la fuente no describe las características de ese meteoro.

1706, 3 de abril. Supuesto bólido observado en Barcelona

Según algunos, durante la batalla apareció sobre Montjuïc un meteoro que formaba la cruz de Santa Eulalia ${ }^{23}$.

Muy dudoso; la forma de cruz oblicua remite al meteoro de 25 de diciembre de 1704 .

1706, 21 o 22 de abril. Supuesto bólido observado en Barcelona

Dos días antes de la muerte del Conseller en Cap, refiere Feliu que apareció sobre Barcelona un Cometa que se extinguió y que no se advirtió al día siguiente $^{24}$.

de Ciento de la capital catalana y formó parte del gobierno provisional catalán durante el sitio de 1713-14; después de la capitulación, sus bienes fueron confiscados por el régimen borbónico. (Diccionari Biogràfic Alberti, 3, pág. 122). Sin duda alguna, se trata del anónimo autor del opúsculo Verídica relación diaria de lo sucedido en el ataque y defensa de Barcelona y en el Principado de Cataluña en el año 1705, que no es más que una traducción parcial del expresado manuscrito.

21 J. Ventalló, Tarrasa antigua y moderna: ensayo histórico, Tarrasa, Impr. La Industrial Norte, 1879, 330 págs

${ }^{22}$ Juizio sobre el celeste señal, que sucediò en el dia 23. del mes de Noviembre deste presente año 1705. que es la confirmacion de aquel prodigioso Señal, que se viò en 25. de Deziembre de 1704, día de la Natividad de Jesv-Christo Nuestro señor, que tanto ha dado que discurrir á los curiosos; y otras Influencias Celestes, que he bien observado, todas favorables á la Casa de Austria, y en particular à nuestro Grande Monarca Carlos Tercero (que Dios guarde) que por no avermelo permitido la libertad, las dexava en silencio. Compuesto por el Doctor en Medicina Juan Solar. Barcelona, B. Giral, 4 págs.

23 «Metheoro sobre Montjuich», en Feliu de la Peña, 1709, vol. 3, pág. 557.

24 Feliu de la PeÑa, 1709, vol. 3, pág. 564. 
Muy dudoso. Feliu utiliza supuestas señales del cielo para subrayar los acontecimientos históricos que narra.

1715, 18 de febrero. Bólido observado en Tarifa (Cádiz) a las 6 horas

A las 6 de la mañana se divisó una asombrosa nube sobre el castillo de Almarza, sito en la costa africana, de la que salió una como vara de fuego gruesa como el muslo de un hombre, que se dividió en tres partes; cabeza negra, cuerpo versicolor y cola de fuego centelleante a modo de estruendosos cohetes; cruzó el estrecho y pasó sobre Tarifa, corriendo dos leguas más al norte; a ojos del observador pareció retroceder luego. El caso fue comunicado por escrito a la Corte y otros puntos ${ }^{25}$.

Se trata de la observación indudable de un bólido, descrito con detalle en verso colorista y estilo barroco.

1723, 6 de enero. Supuesto bólido observado en Portugal

Citado en el catálogo de Greg (1861), sin otra información.

Muy dudoso; desconocemos la fuente de esta noticia.

1743, 31 de agosto. Supuesto bólido observado en Barcelona a las 22.15 horas

Ese día se vio por la parte de mediodía un gran globo de luz que despedía gran resplandor; duró poco ${ }^{26}$.

Dudoso, atendiendo lo ambiguo y único de la información.

1750, 26 de julio. Supuesto bólido observado en A. dos Cunhados (Torres Vedras), a las 21.30 horas

25 Relación verdadera, copiada de una carta escrita por un Cavallero de la Ciudad de Tarifa, à otro de esta Corte, en que le da cuenta de un Prodigioso Meteoro, o Cometa, que apareciò en el Cielo, entre seis, y siete de la mañana del día diez y ocho de Febrero de este presente año de mil setecientos y quince, sobre el Castillo, y Fortaleza de Almarça, situado en las Costas de Berbería: Refierese por estenso todas sus señales, tamaño y forma, con las demàs circunstancias con que se dexò ver, y el curso que siguiò en su carrera, hasta que se desapareció con los movimientos que verà el curioso (Madrid, 1715).

26 En dos manuscritos del convento de Santa Caterina de Barcelona: Varias noticias desde el añy 1711 en avant, por Francesc Clarasó y Lumen Domus, III, pág. 342. Ambos en la Biblioteca de la Universidad de Barcelona: volumen misceláneo B-54/1/1 y Ms. 1007, respectivamente. El primero parece ser un borrador del segundo. 
Entre 9 y 10 de la noche se observó ese día una señal roja en el cielo, a modo de espada, desde el NO sobre el mar hacia al sur, hasta llegar al SE en que ya no se percibía; por el camino fue perdiendo su rojez ${ }^{27}$.

Muy dudoso, podría tratarse de una aurora.

1755, 29 de julio. Bólido observado en Sevilla, Carmona y Peñaflor, a las 20 horas

Entre 8 y 9 de la noche se vio desde Sevilla una exhalación que iluminó como la luna; corrió un gran trecho dirigiéndose del SO al NO; al fin de su carrera se dividió en tres partes, dando un gran trueno como un cañonazo. Desde Peñaflor se le vio también a poniente; se apreció su duración en dos minutos y se comparó el ruido de la explosión al de un temblor de tierra. En Carmona se apreció la duración del trueno en tres minutos. Desde Carmona se le vio correr de E a O; desde Sevilla, de SO al NO. Debe corresponder a la misma exhalación que los de Espera (Cádiz) declararon haber visto en un día inconcreto del mes de agosto ${ }^{28}$.

Bólido indudable, descrito de forma coherente por varios observadores en un área de unos $350 \mathrm{~km}^{2}$.

1755, 1 de noviembre. Supuesto bólido observado en diversos puntos del SO peninsular

En las respuestas a las encuestas oficiales llevadas a efecto en España y Portugal a raíz del terremoto de Lisboa se citan diversas observaciones de señales en el cielo que algunos calificaron de «cometa». Se habrían observado en numerosas localidades del SO peninsular a lo largo de la noche anterior e incluso en otras noches anteriores y posteriores. Algunos declararon haber visto salir de la tierra o incluso del mar exhalaciones encendidas, lo que está de acuerdo con la concepción que de los terremotos se tenía en la época ${ }^{29}$.

27 F. L. Pereira de SOUSA, O terremoto do $1^{\circ}$ de Novembro de 1755 em Portugal e um estudo demografico, Lisboa, Serviços Geologicos, 3 vols., 1919-1932, vol. I, págs. 235-236.

28 J. M. Martínez Solares, Los efectos en España del terremoto de Lisboa (1 de noviembre de 1755). Madrid, Instituto Geográfico Nacional, 2001, 756 págs., las referencias en las págs. 599, 514, 261 y 385 respectivamente.

29 Pereira de Sousa, O terremoto do $1^{\circ}$ de Novembro de 1755; Martínez Solares, Los efectos en España del terremoto de Lisboa. Lo que está de acuerdo con las ideas de la época sobre el origen de los terremotos a partir de la inflamación y explosión de gases subterráneos en el interior de la tierra (no fue hasta 1760 que se empezó a asociar los terremotos con los desplazamientos de ondas en la tierra). En ocasión del terremoto de Palermo (1/09/1726), además de una columna luminosa que se vio precipitarse en el mar, se observó azufre generado en el interior de grietas abiertas en el terreno (M. SILVESTRI, Introduzione alle luci sismiche, 1999-2001; 
Pereira, en su estudio sobre el terremoto, cita luces semejantes observadas durante los seísmos del Algarve (27/12/1722) y Madeira (1/04/1748); las califica de «fenómenos electro-luminosos de los terremotos», supone que se producen a consecuencia de las sacudidas (incluyendo las premonitorias y las réplicas) y propone un origen derivado de la ionización producida por supuestas emanaciones radioactivas ${ }^{30}$. Para Martínez Solares ${ }^{31}$, en cambio, un cometa habría cruzado el cielo entre 5 y 6 horas antes del movimiento sísmico; en el estudio de 2001 este autor no duda de la veracidad de tales observaciones; reconoce que no fue un suceso puntual, apunta que no parece tratarse de un fenómeno meteorológico y se inclina a considerarlo como la observación del paso de un meteorito, o de su impacto contra la atmósfera terrestre. Sin embargo, tanto la duración extremadamente prolongada del fenómeno como su repetición en sucesivos días permite descartar que se trate de uno o más bólidos; habría que pensar en otros fenómenos, bien del tipo de las auroras o bien meteorológicos.

\section{5, 15 de Noviembre. Supuesto bólido observado en Osuna (Sevilla)}

Desde Osuna se observó un 'candilejo' con gran resplandor hacia el Mediodía, alumbrando de tal modo que se veían los olivares hasta a media legua de distancia. Era la noche del sábado 15, poco después del toque de oración ${ }^{32}$.

Dudoso; se trata de una noticia única y poco concreta.

1755, 22 de Noviembre. Bólido observado desde Hostalric y Caldes de Malavella (Girona), a las 18.45 horas

Como a las 6.30 horas de la tarde dos paisanos de Hostalric vieron por la parte de mediodía un gran señal en forma de barra de fuego, que fue a parar a la parte de cierzo; al extinguirse oyeron un gran ruido en el aire. Varios habitantes de la villa la vieron pasar por encima. Desde Caldes de Malavella se vio como a las 7 de la

\footnotetext{
http://www.itacomm.net/EQL/eql01_i.htm). Para explicar el de Umbría de 1751 se propuso que las cavernas subterráneas cubiertas de azufre y llenas de agua constituían generadores eléctricos responsables de la descarga que causó el terremoto. Durante el sismo de Rímini (1786), se aseguró que una columna de fuego atravesó el cielo de la ciudad poco antes del movimiento En el siglo XIX Ignacio Galli intentó sistematizar las «luces sísmicas» asociadas a los terremotos ocurridos en Italia; su tipología resulta ser muy diversa: luminosidad difusa, o concentrada en columnas, planos y esferas; descargas eléctricas, pequeñas llamas, etc. (C. Fidoni: Emisión eletromagnetiche e terremoto in Italia; página web).

30 F. L. PEREIRA DE Sousa, «Sur les phénomènes lumineux observés pendant quelques tremblements de terre au Portugal», Société Géologique de France, Compte-Rendu véanse, 13 (3/11/1930), págs. 160-162.

31 J. M. Martínez Solares, et al., «Isoseismal map of the Lisbon Earthquake obtained from Spanish data», Tectonophysics, 53 (1979), págs. 301-313.

32 Martínez Solares, Los efectos en España del terremoto de Lisboa, pág. 497.
} 
noche hacia Poniente un «cometa» que se dividió en dos, desplazándose una parte hacia el Cierzo (duró un Avemaría) y la otra al Mediodía, oyéndose inmediatamente después dos o tres estruendos ${ }^{33}$.

Dos observaciones coincidentes otorgan credibilidad a este caso.

1755, 28 de diciembre. Supuesto bólido observado en A. dos Cunhados

Según un manuscrito del cura Antonio Duarte, ese día hubo hacia las 10 de la noche una señal en el cielo que al parecer se abrió, iluminándolo todo como si fuera de día y volviéndose a cerrar, surcó una centella de fuego para la parte del sur ${ }^{34}$.

Dudoso, a falta de otras observaciones que lo confirmen.

1766, 2 de junio. Bólido observado en Cataluña a las 21.45 horas

Ese día, a las 9.45 de la noche, estando la luna menguante y la temperatura en $65^{\circ} \mathrm{F}$, en Barcelona: «Oiose un trueno azia â la parte del sudueste o leveche semejante al del estruendo de un cañonazo disparado en lo interior del mar, aparecio despues por la misma parte una luz que siguió al Phenom ${ }^{\circ}$, en cuia situacion perpendicular sobre esta ciudad fue tal la luz que despedia que excedio á la de la luna en el lleno, despidiendo algunas centellas. El color era en su parte posterior algo roxa, y en las posterior mas blanca. Su figura era semejante a la de un cono truncado con su parte anterior convexa. Su longitud aparente cosa de 2 pies, su latitud por la parte anterior de 5 a 6 pulgs. Por la posterior terminaba en una pulgada, su altura varió al par que fue caminando como se dirá, la que aquí se le pudo observar no era mucha, y parecia que iba disminuyendo mas al passar. No se le pudo notar que dexase rastro alguno, ni que se percibiese edor ninguno. Celeridad no era mucho respeto de lo que se observó en otros. Se oió al passar algun leve silvido. Pareció â algunos aumentar su magnitud al despedirse, y continuó su curso azia el Nordeste. Se sabe haberse visto en la parte de Villafranca, de donde no se tiene individuación. En Vilamajor truenos y passó Montseny y se perdió. Compareció mas tarde en Breda [...] Falta para la completa descripcion su origen, y su termino, que con el tiempo se sabrá tal vez» ${ }^{35}$.

En la versión definitiva de su memoria, Desvalls asegura que se le vio a la misma hora en Poblet; también en Arenys, con una luz mucho mayor y con fuerte estallido, que causó conmoción en puertas y cristales de las casas. También fue

33 F. Rodríguez de la TORRe, «Repercusión en tierras de Girona y del Maresme del gran terremoto de Lisboa (1 de noviembre de 1755)», Anales del Instituto de Estudios Gerundenses, 2 (1984), págs. 329-357; referencia en la pág. 360; Martínez Solares, Los efectos en España del terremoto de Lisboa, pág. 248.

34 Pereira de sousa, $O$ terremoto do $1^{\circ}$ de Novembro de 1755, pág. 835.

35 Informe ú observaciones sobre un fenómeno llamado globo ígneo; mss. de la Real Academia de Ciencias y Artes de Barcelona, atribuible a J. A. Desvalls i d'Ardena. 
sensible su estallido en Vilamajor y algunos afirmaron haberla visto pasar al otro lado del Montseny. En Breda se le vio con mayor magnitud que en Barcelona, luz muy sensible, con el diámetro aparente de la luna y una cola como de dos varas que despidió copiosas chispas; se oyeron allí dos truenos tan fuertes que hicieron temblar las casas y se extinguió sobre el castillo de Montsoriu. Vióse también en Gerona y Olot, con igual luz y estruendo que en Vilamajor ${ }^{36}$ (figura 3).

Bólido indudable que suscitó el interés de la Conferencia Phisico-Mathematica Experimental, que comisionó a su principal impulsor J. A. Desvalls y se reunió el 4 de junio a instancias del marqués de la Mina con el fin de que expusiera su parecer sobre las causas del fenómeno. Se le vio en localidades distantes 120 km como máximo; al parecer su explosión se produjo sobre el extremo oriental del Montseny.

1769, 4 de julio. Bólido observado en Cádiz a las 23 horas

El dia 4 á las 11 en punto de la noche se observó una exhalacion, cuyo movimiento fue de $\mathrm{O}$ á $\mathrm{E}$, este fenomeno iluminó toda la Ciudad con una luz tan singular, que excedió en mucho á la que nos comunica la luna quando está en el plenilunio en una noche serena, dicen algunos que como cosa de dos minutos despues se oyó un ruido como si fuera un trueno que se oyera de muy lexos, pero esto no se asegura por ser muchos mas los que dicen que no oyeron tal ruido ${ }^{37}$.

1769, 7 de diciembre. Supuesto bólido observado en Mataró a las 4 horas

Cerca de las cuatro de la madrugada apareció un globo de fuego por la parte de septentrión despidiendo rayos de fuego; se dirigió a poniente y a poco se desvaneció con un estruendo tal que muchos se despertaron ${ }^{38}$.

Dudoso; se trata de una noticia no confirmada.

1773, 17 de noviembre. Meteorito caído en Sigena (Huesca) a las 12.30 horas Ese día se vio caer una piedra del cielo en las proximidades del Real Monasterio de Sigena, equidistante unos $2 \mathrm{~km}$ de los lugares de Sena y Villanueva de

36 J. A. Desvalls, «Observación del fenómeno celeste de 2 de junio de 1766», [1766], apud. J. IGLÉSIES, «La Real Academia de Ciencias y Artes en el siglo XVIII», Memorias de la Real Academia de Ciencias y Artes de Barcelona, 36, 1 (1964), 635 págs., figura 3.

37 «Observaciones meteorologicas de Cádiz, correspondientes al mes de julio», Memorial literario, 15 (69), pág. 77.

${ }^{38}$ Llibreta de les antiguidats de Mataró y altres noticias que van succehint per puliticas, manuscrito del Archivo Fidel Fita de Arenys de Mar. 


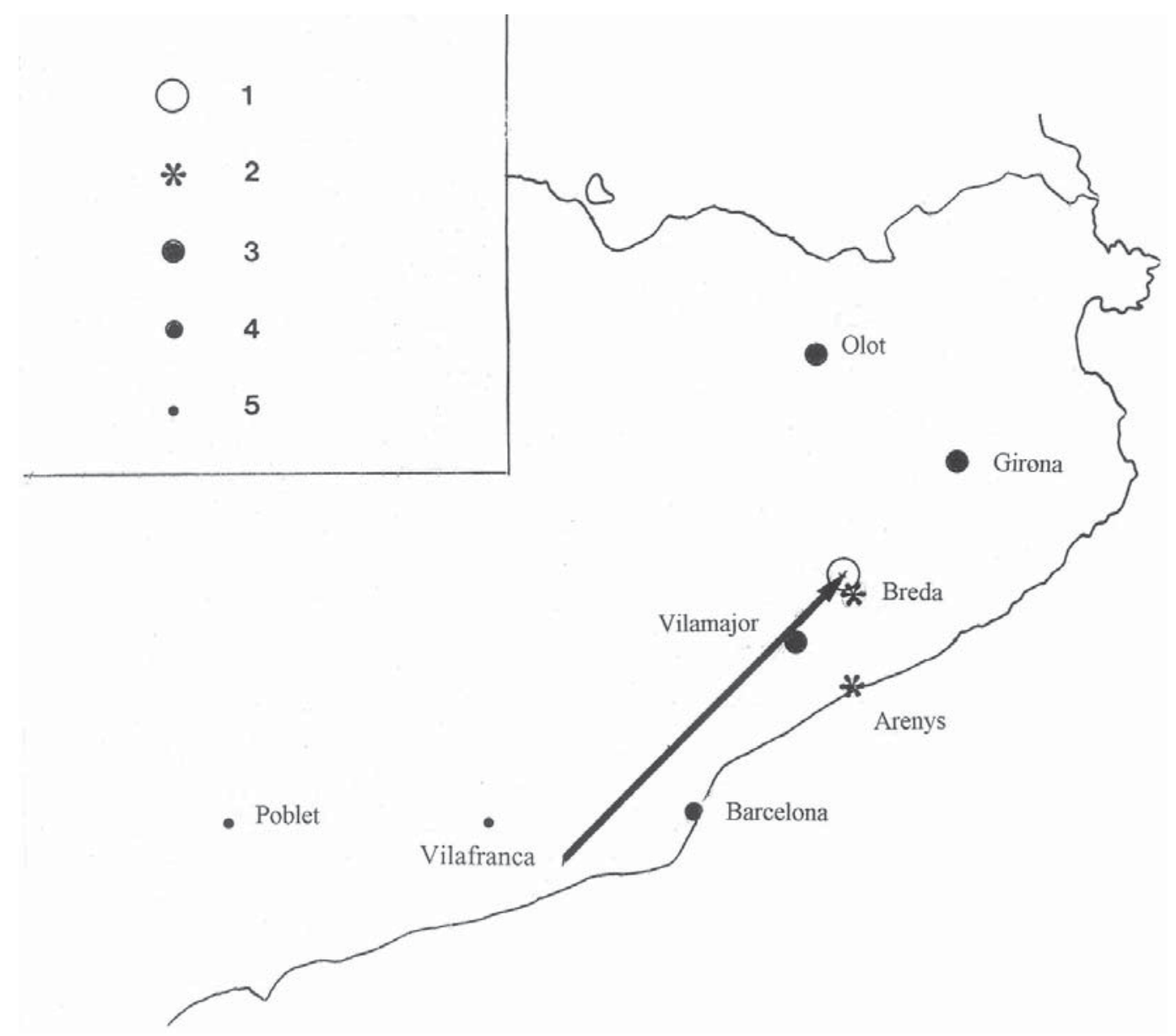

Figura 3. El bólido de 2 de junio de 1766, según Desvalls. 1, punto de extinción; 2, vibraciones; 3, estruendo notable; 4 , observación sin estruendo; 5 , otras observaciones.

Sigena, en la provincia de Huesca. A los pocos días, Antonio Aguirre, médico del cabildo de la catedral de Tarazona y de esta ciudad dio cuenta del suceso en una carta fechada el día 28 de noviembre y dirigida a un amigo suyo; se publicó en Zaragoza con fecha de 1774. En ella, dice Latassa que el autor «filosofa con razones, y erudición propia del suceso de esta naturaleza» ${ }^{39}$.

39 A. Aguirre, «Carta Filosófica sobre un Fenómeno de los más peregrinos de estos tiempos, sucedido a 17 del presente mes de Noviembre de este año de 1773, en las cercanías del Real Monasterio de Sixena, Diócesis de Lérida, partido de Barbastro, del Reyno de Aragón». (Zaragoza, F. Moreno, 1774, 15 págs). Dio un breve resumen de este escrito junto con una noticia de su autor F. Latassa (F. LATASSA y Ortín, Biblioteca Nueva de los escritores aragoneses. Pamplona, 1801, tomo V, págs. 300-301). Según dicho autor, Antonio Aguirre [1716-1779] débese reputar por natural de Alcañiz no obstante su nacimiento casual en la Villa de Rosas en Cataluña en 29 de noviembre de 1716, pues su padre D. Miguel era militar y natural de aquella ciudad (cita recogida por E. MAFFeI, \& R. RÚA FigueROA, Bibliografía mineral hispano-americana. Apuntes para una biblioteca española de libros, folletos y artículos, impresos y manuscritos, relativos al conocimiento y explotación de las riquezas minerales y á las ciencias auxiliares, Madrid, Lapuente, 1871-1872, 2 vols.) 
El caso suscitó el interés del capitán general de Aragón Antonio Manso quien, después de una entrevista con sujetos eruditos, encargó una investigación al justicia de Sena y reclamó la piedra; requerimientos que fueron cumplimentados por el alcalde de Sigena; hubo además una segunda averiguación a cargo del susodicho alcalde. Manso pasó el expediente, junto con el meteorito, a la Real Casa, el día 5 de febrero de 1774, a través de don Manuel de Roda. Ambas piezas se conservan actualmente en el Museo Nacional de Ciencias Naturales de Madrid ${ }^{40}$.

En 1803, Luis Proust analizó el meteorito «caído cerca de Sirena» y publicó sus resultados, dándolos a conocer en el Journal de Physique junto con los pormenores de la caída ${ }^{41}$. Se menciona esta caída en Balcells como «Sena de Aragón» ${ }^{42}$, en el catálogo de Greg como «Sigena, Aragon», en Meteoritos de Faura como «Sigena (Villanueva de)», y en Martín Escorza («Fenómenos») como «Sena».

Circunstancias de la caída: El 17 de noviembre de 1773 estaba siendo un día «sin aparato de tempestad» en la huerta de Sena, pero entre las 12 y las 13 horas se oyó por tres veces un ruido extraordinario, y casi inmediatamente después cayó una piedra de «nueve libras y una onza de peso» en las inmediaciones de dos hombres que se encontraban en sus tierras de labor. Según los datos recogidos entonces, la piedra parecía venir desde «entre norte y poniente» y su trayectoria no fue vertical sino «curva» El impacto produjo un hoyo de no mucha profundidad sobre esa tierra y de tal agujero la piedra rebotó yendo a depositarse sobre el suelo a corta distancia. El punto de caída se encontraba dentro de la propiedad de Francisco González, contigua a la de Manuel Calvo, ambos se encontraban en esos momentos comiendo sobre el terreno, y tanto ellos como los animales se asustaron. Según Aguirre, la piedra fue arrojada por unas nubes débiles y sueltas.

Meteoritos. Después de ese primer desconcierto uno de ellos, Manuel Calvo, se acercó al punto de caída aunque le retrajo el olor fétido que sintió; se esperó un tiempo y acercándose de nuevo tocó al meteorito con la azada, lo hizo después con la mano pero la retiró de inmediato pues la piedra todavía estaba caliente. Debemos suponer que tras otro tiempo de espera, recogió el meteorito, en el que observaron que le faltaba una esquirla que trataron de recoger excavando en el agujero del impacto, pero no la hallaron. Así que Manuel Calvo lo metió en su

40 MNCN, Archivo, Carpeta 169. Algunos de los documentos fueron transcritos y publicados por Jimeno (H. Jimeno, «Noticias históricas sobre algunas piedras meteóricas caídas en España», Boletín de la Sociedad Española de Historia Natural, 1, 1901, págs. 224-226). De ellos Faura (1922) transcribe la carta de Manso a Roda.

41 L. Proust, Análisis de una piedra meteórica caída en las inmediaciones de Sixena en Aragon, el 17 de noviembre de 1773, Madrid, s/i, 40 págs.; resumen en: Variedades de literatura y artes, 3 (1804) 193, 257; L. Proust, «Sur une pierre meteorique tombée aux environs de Sigena, en Aragon, dans l'année 1773», Journal de Physique, de Chimie et d'Histoire Naturelle, t. LX (1805), págs. 185-205.

42 J. Balcells, Lithologia meteorica, Barcelona, F. Granell, 1854, 119 págs. 
«chupa» y lo llevó a Sena donde se la presentó al cura Antonio Pano quien de inmediato se quedó con la piedra.

El ejemplar, pesado mediante una balanza «romana», dio un peso de «nueve libras y una onza». Después de lo sucedido la noticia recorrió toda la zona y muchos vecinos fueron a Sena para ver la piedra a la que unos y otros arrancaron pequeñas porciones que se llevaron para enseñar a sus familiares y amigos. Así que después de ese primer despiece el ejemplar se quedó en un peso de «ocho libras y nueve onzas». En la mencionada obra de Aguirre, se describe el meteorito como «muy semejante a la escoria del hierro, sacada de la Fragua, o al Antimonio muy atezado».

En días sucesivos aparecieron hasta cinco fragmentos más: a los dos días de la caída Manuel de La Casa encontró dos de ellos en un campo de la huerta del Real Monasterio. Y no se sabe cuándo exactamente, pero en esas fechas, unos muchachos encontraron otro, el cual entregaron a Miguel Ferrer, presbítero del Monasterio, quien a su vez lo remitió al sacerdote Joseph Cuber. Posteriores averiguaciones del alcalde de Sigena dieron como resultado la recuperación de dos nuevos fragmentos.

Investigación. Lo insólito del caso motivó que el capitán general de Aragón, Antonio Manso, iniciara una investigación:

No me pareció mirar con indiferencia este fenómeno, y después de haber hecho conversación de él con varios sujetos de conocida erudición, me determiné a prevenir a la justicia de Sena que hiciese una información formal del suceso y me remitiese la piedra, con seguridad de ser la misma de que trata. En cumplimiento de mi disposición me envió la información el alcalde de Sixena y la piedra en una caja sellada con las armas del monasterio de Religiosas del Orden de San Juan, de cuyo señorío es el territorio, y las mismas religiosas me enviaron otro pedacito de piedra igual a la grande, que se cree parte de ella, por medio del Recibidor de Malta de este Reyno. Luego que tuve la información y el cajoncito, abrí este en presencia del Muy Reverendo Arzobispo, de D. Juan Tomas de Micheo [...]: se vió la piedra, y se discurrió sobre su especie, caída y otras circunstancias, resultando de esta conversación, que se encargase D. Miguel de Villava que hiciese algunas preguntas al alcalde de Sixena. El alcalde de Sixena se dedicó a la averiguación para informar a las preguntas y me envió la información que nuevamente se le había pedido, y en ésta se halla contestado el extraordinario ruido repetido tres veces el dia 27 de noviembre con admiración de unos, susto de otros, y con uniforme comprobación de él; siendo de advertir que no hay quien diga que precedió el relámpago, como es regular en las tempestades [...] Con las segunda información me envió el alcalde de Sixena dos pedacitos más de piedra, los cuales puse con la grande, y habiendo 
hecho hacer análisis del que ya he dicho, me entregó el Recibidor de Malta, se hallan las partes separadas, que contiene otro papel con su rotulata que lo indica. Me ha parecido que tanto la piedra grande como las pequeñas, y la que por medio de operaciones practicadas por el perito se halla con separación de partes, con las informaciones hechas en el asunto merece hacerse presente al Rey; Para este fin dirijo todo a V. E. suplicándole, que lo eleve a su Real conocimiento ${ }^{43}$.

\section{4, 20 de julio. Supuestos bólidos observados en Madrid}

Refiere el observador meteorológico del Memorial literario que ese día se vieron exhalaciones por la noche.

Dudoso; podría tratarse de estrellas fugaces.

\section{6, 11 de abril. Bólido observado en Moura (Beja), a las 19.30 horas}

Hacia las 7.30 horas de la noche se observó un meteoro que asustó mucho a los que lo vieron, y puso en guardia a los demás que percibieron sus efectos. Soplaba en dicha hora un viento suave del oeste; el cielo estaba limpio de nubes, y la noche serena y clara a la luz de la luna; entonces se vio correr una exhalación que pareció dirigir su curso por encima del extremo oriental de dicha villa, con una altura aparente de 300 pies, bajando hacia tierra. La cabeza de este cuerpo luminoso era esférica y su diámetro en poco difería del de la luna llena en el cenit; le seguía una cola de poco más de una vara de largo, todo de una luz clara; de su extremidad salía una antorcha de fuego despidiendo abundantes chispas que parecían caer a la tierra. La claridad que produjo ofuscó por completo la luz de la luna, y a los 8 o 10 minutos se oyó un estruendo semejante al de una gran pieza de artillería; por espacio de 6 minutos se sintió un ruido a modo de trueno subterráneo. El aire conservó la misma serenidad después del fenómeno, cuya dirección fue de NE a SO. En dos aldeas del término, Santo Aleixo y Safora, a dos leguas de distancia hacia el oriente, se oyó el

43 Carta de A. Manso a M. de Roda, 5/02/1774, transcrita por Jimeno, «Noticias históricas» y reproducida por Faura, Meteoritos. Se conserva en el MNCN, exp. 169, junto con los documentos siguientes: Comunicación de Manso al alcalde de Sigena para que le envíe todas las noticias, además de la piedra recuperada, 30/11/1773; Nota de don Manuel Martínez a Manso, remitiéndole la información solicitada, 6/12/1773); acompaña las «Informaciones hechas por el alcalde del distrito y territorio del Real Monasterio»; Notificación de don Miguel de Villava (oidor de la Real Audiencia de Zaragoza) al alcalde de la Real Casa de Sigena solicitando más información y testimonios de los testigos; Comunicación de don Manuel Martínez remitiendo las diligencias practicadas y dos pedacitos de la piedra en cuestión recogidos por Manuel de la Casa, según certificado de don Miguel Ferrer, presbítero racionero del Real Monasterio (1/01/1774), acompaña la sumaria información citada, cosidos en el informe de don Antonio Pan, prior párroco de Sena, dirigido a don Manuel Martínez por orden de don Gabriel Antonio Junqueras; Notificación de don Miguel de Villava. (M. A. Calatayud, Catálogo de documentos del Real Gabinete de Historia Natural (1752-1786), págs. 84, 86-87). 
mismo estruendo y se divisó el mismo fenómeno hacia poniente; dado que desde esta villa se vio hacia el oriente, dedujo el informante que el meteoro pasó por entre ella y las mencionadas aldeas ${ }^{44}$.

Descripción indudable de un bólido.

1788, 18 de mayo. Bólido observado en La Solana (Ciudad Real), a las 18 horas

Apareció de improviso a las 6 de la tarde una larga y gruesa barra de plata que culebreando se dirigió velozmente, horizontal al principio, pasó por encima de la villa y se introdujo en una nube, dejando un rastro de al parecer tres o cuatro varas de largo de humo blanquecino como de un tiro de cañón del mayor calibre; al introducirse en la nube se oyó un trueno mucho más fuerte, duradero y profundo que los ordinarios ${ }^{45}$.

La descripción corresponde a la de un bólido.

1788, 9 de junio. Supuesto bólido observado en Fuente del Maestre (Badajoz)

Según la Gaceta de Madrid, se observó ese día un globo de fuego.

Muy dudoso; podría tratarse de la caída de un rayo.

1789, 6 de septiembre. Bólido observado en Barcelona entre las 20 y 21 horas

Según publicó el doctor Salvà i Campillo en el Memorial Literario, se le vio en distintas partes de Cataluña; era como un globo de fuego que se desprendía del cielo; ofuscó brevemente la luz de la luna llena. Si bien Salvà no lo observó personalmente, lo compara a los observados en 1771, 1774 y 1783 descritos por Delalande, Forster, Dagelet y otros ${ }^{46}$.

Puede tratarse de un bólido, con algunas reservas.

1790, 24 de julio. Bólido observado desde Barcelona sobre las 21 horas

Según observó personalmente Salvà, era un globo de fuego que corrió como cuatro varas de NNO a N; parecía del tamaño de una sandía, y al extinguirse se partió en tres o cuatro centellas de luz tan clara y hermosa como la del globo ${ }^{47}$.

\footnotetext{
44 Códice 906 de la Biblioteca Nacional de Lisboa, citado por Pereira DE SOUSA, $O$ terremoto do $1^{o}$ de Novembro de 1755, vol. I, págs. 235-236.

45 Carta de don Alfonso Tabares al señor Diego Peñalosa, publicada en el Memorial Literario, 14, págs. 664-667.

46 Memorial literario, 16, pág. 372.

47 Memorial literario, 18, pág. 372. También en: «Carta del doctor don Francisco Salvá a los Compositores del memorial Literario, sobre el terremoto experimentado en Barcelona el 16 de julio de 1790», Memorial literario, 21, 117 (Sept. 1790), págs. 61-65.
} 
Se trata, sin duda alguna, de la observación desde Barcelona, de la caída meteorítica de Barbotan, en la región del Armagnac, al SO de Francia ${ }^{48}$.

\section{0, 29 de julio. Bólido observado en Barcelona}

Asegura Salvà en el mismo artículo que el día 29 hubo otro bólido mucho más pequeño ${ }^{49}$.

Dudoso; por su escasa magnitud puede que se tratara de una estrella fugaz.

\section{0, 1 de septiembre. Bólido observado en Barcelona}

Según el mismo autor, otro bólido se observó el primero de septiembre ${ }^{50}$.

Dudoso; por su escasa magnitud puede que se tratara de una estrella fugaz.

1791, 5 de julio; supuesta explosión de un bólido oída en Sabadell, a las 18 horas

A las 6 de la tarde los que se encontraban fuera de la ciudad percibieron un ruido muy fuerte y remoto, que fue disminuyendo paulatinamente, alargándose; al parecer no era subterránea ${ }^{51}$.

Muy dudoso; faltan las observaciones visuales.

1791, 26 de octubre. Bólido observado en Los Rábanos (Soria)

48 Ese día, entre las nueve y las diez de la noche, apareció un globo brillante con una larga cola luminosa que se observó durante unos 50 segundos en una gran área de la Francia meridional. Poco después se oyó una formidable explosión, que precedió la caída de piedras en varios puntos diferentes de las proximidades de Barbotan, localidad situada unos $40 \mathrm{~km}$ al E de Mont-de-Marsan. Resulta del proceso verbal instruido por el alcalde de la comuna de Mexin que las piedras cayeron a unos 10 pasos unas de otras; la mayor parte no pesaron más de medio cuarto de libra; algunas entre una y dos libras. Se asegura que una dio cerca de 25 libras fue llevada a Mont-de-Marsan, y que varias fueron llevadas a París, de las que dos pesaron entre 25 y 30 libras. En el catálogo de Izarn (en U. B. Marvin, «Ernst Florens Friedrich Chladni») aparece duplicado: 24/07/1790: lluvia de piedras (St. Amans, Baudin, etc) y julio de 1789: lluvia de piedras, Barbotan, cerca de Roquefort (Darcet hijo, Lomet, etc). Viene en Balcells 1854 como «Borbotan cerca de Burdeos». En el catálogo actual de meteoritos de Francia aparece como Barbotan: Condrita H5 veteada caída el 24 de julio de 1790 hacia las 21 horas. Peso $15 \mathrm{~kg}$.

49 Memorial literario, 18, pág. 372. También en: «Carta del doctor don Francisco Salvá a los Compositores del memorial Literario, sobre el terremoto experimentado en Barcelona el 16 de julio de 1790», Memorial literario, 21, 117 (Sept. 1790), págs. 61-65.

50 Ibid.

51 A. Bosch i Cardellach, Memoria de las cosas notables de la vila de Sabadell comensant en desembre de 1787. Sabadell, Ed. Mediterránea / Fundació Bosch i Cardellach, 2003, pág. 127. 
Según Sáez, el cura párroco Francisco Ruperto Enríquez describió con detalle el fenómeno, citándolo como «caída»; si bien no se tienen noticias de que se haya conservado muestra alguna ${ }^{52}$.

En Martín Escorza figura como «caída», siguiendo el relato de Sáenz ${ }^{53}$. Sin poner en duda la descripción del observador, teniendo en cuenta su solvencia como arqueólogo, resulta problemático inferir que se recuperara un meteorito, ante la falta de otras evidencias. Téngase en cuenta que los bólidos también «caen».

1795, 19 de agosto. Bólido observado en Los Rábanos (Soria)

Segunda observación relatada por la misma fuente anterior ${ }^{54}$.

Martín Escorza la cita como «impacto meteorítico». Véase la nota anterior.

1796, 19 de febrero. Meteorito caído en Tasquinha (Alentejo) sobre las 13.30 horas

La primera caída documentada de un meteorito en territorio portugués es la que tuvo lugar cerca de Évora Monte en 1796. El 19 de febrero de aquel año, entre la una y las dos de la tarde, se vio caer un cuerpo del cielo en el lugar llamado Tasquinha, término de Évora Monte, provincia de Alentejo.

La Gazeta de Lisboa dio noticia del suceso, fechada el 15 de marzo de 1796, en el número correspondiente al 22 de marzo, situando la caída en las proximidades de San Miguel de Machede ${ }^{55}$. Poco después, el escritor inglés Robert Southey ${ }^{56}$, que a la sazón se encontraba en Portugal, consiguió una copia de la deposición hecha por testigos ante Elias Antonio, juez de paz de Évora Monte, y la incorporó, en portugués con traducción al inglés, en su libro de viajes, que sigue siendo la principal fuente de información sobre las circunstancias de la caída.

52 Sáenz tuvo la oportunidad de leer directamente lo escrito por el cura párroco acerca de diferentes sucesos ocurridos en la zona (C. SÁENZ, «Un descubrimiento prehistórico en el siglo XVIII», Asociación Española para el Progreso de las Ciencias, Congreso de Lisboa, 5, 1932, págs. 129-136). En el verano de 1987 uno de nosotros tuvo ocasión de consultar el libro tercero de los bautizados comprobando que las páginas finales, donde deberían de encontrarse las noticias, habían sido arrancadas (C. MARTín Escorza, «Fenómenos meteoríticos ocurridos en España»). En esas páginas, según en parte las trascribe Sáenz, se relataban las exploraciones de algunas de las cuevas existentes en las calizas mesozoicas de la zona, en las cuales Enríquez encontró materiales prehistóricos de interés, por lo que con ese motivo interesaron a alguien entre 1932 y 1987.

53 C. Martín Escorza, «Fenómenos meteoríticos ocurridos en España».

54 C. SÁENZ, «Un descubrimiento prehistórico en el siglo XVIII».

55 Transcripción en Pereira de sousa, O terremoto do $1^{\circ}$ de Novembro de 1755, pág. 881.

56 Robert Southey (1774-1842), poeta, novelista y conspicuo intelectual inglés de la época, escribió ensayos biográficos e históricos; como hispanista, tradujo al inglés obras clásicas como El Cid y Amadís de Gaula. La caída del meteorito coincidió con uno de sus períodos de residencia en Portugal, donde contaba con el apoyo de un familiar residente en Lisboa. 
En 1802 el químico Edward Howard leyó una comunicación en la Royal Society de Londres citando como autoridad la descripción de Southey ${ }^{57}$. El propio Chladni se hizo eco de la caída. En el catálogo de Greg figura con el nombre de «Friexo», por el río Freixo. En los catálogos de Graham y Grady ${ }^{58}$ consta como «Portugal». Faura conserva el nombre original («Tasquinha») pero equivoca el día (10 en lugar de 19), error que se repite en los catálogos de Llarena y de Paluzie $^{59}$. Monteiro lo cita como «Tasquinha». Recientemente ha sido estudiado por Ursula Marvin ${ }^{60}$.

Circunstancias de la caída. Se lee en la Gazeta de Lisboa de 22/03/1796:

El rumor que ha corrido por aquí acerca de un volcán que rompiera en el Alentejo, tiene por fundamento el haberse oído en las cercanías de San Miguel de Machede un estruendo subterráneo, que fue seguido por otro, similar a una explosión, y haberse visto caer una piedra aún caliente, que se juzgó expelida del interior de la tierra, y venir de la parte de la Sierra de Ossa; pero hasta ahora no consta haberse descubierto la abertura por donde fue arrojada; su peso era de más de diez arrateles ${ }^{61}$; en parte era de material calcáreo, y en parte de una especie de lava $^{62}$.

En su escrito, el juez Elías Antonio aseguró haber oído un par de estampidos similares a «explosiones de minas», después de los cuales percibió «un gran estruendo que duró alrededor de dos minutos», y que parecía «ir de norte a este». En aquel momento el horizonte era claro y el cielo despejado, sin nubes. Por su parte Gregorio Calado, labrador del vecino término de Redondo, dijo que también oyó el mencionado ruido y que al cabo de un rato un criado suyo, llamado Joze Fialho, le trajo una piedra que, según él, había visto caer y que había recogido cerca de donde se encontraba, en una parcela de la heredad de

57 E. Howard, «Experiments and observations on certain stony and metalline substances, which at different times are said to have fallen on the Earth; also on various kinds of native iron», Philosophical Transactions of the Royal Society of London, 92 (1802), págs. 168-175; 179-180; 186-203; 210-212.

58 A. L. Graham A. W. R. Bevan \& R. Hutchison, Catalogue of Meteorites, London, British Museum (Natural History), 1985 (4th edition), 460 págs.; M. M. Grady, Catalogue of meteorites.

59 Faura extrae la noticia de A. Ben Saude, Comunicaçoes da Com. Trab. Geol. de Portugal, 1888, t. 2, pág. 24, quien a su vez la toma de los catálogos de Chladni (1919) y Kesselmeyer.

60 J. F. Monteiro, «Portuguese meteorites: Current studies, present knowledge and future prospects», en J. Martínez Frías, y J. Madero Jarabo, (coords.), Meteoritos y Geología Planetaria, Diputación Provincial de Cuenca, 2005, págs. 83-91; U. B. Marvin, «The meteorite fall al Evora Monte, Portugal, 1796», Proceedings of the 26th INHIGEO Symposium, Centro de História e Filosofia da Ciência e da Técnica, Universidade de Aveiro, 2003, págs. 281-290.

${ }_{61}$ Antigua medida de peso utilizada en Portugal. El «Standard de Lisboa» (www.size.com) sitúa la equivalencia en $459 \mathrm{~g}$, tal como lo recoge la Enciclopedia Espasa.

${ }^{62}$ Según la transcripción publicada por Pereira de Sousa, pág. 881; traducido del portugués. 
Tasquinha, en Évora Monte. La piedra en cuestión se hallaba «hundida en el suelo, aún caliente, y el suelo estaba recién removido». Cuatro zagales que se hallaban en el lugar afirmaron lo mismo ${ }^{63}$.

Meteorito. La única pieza que pudo recolectarse era, según testimonio recogido por el juez Antonio, «de color del plomo, pesaba diez libras y tenía forma irregular». Su peso, según él era de 10 libras, y según la Gazeta de Lisboa, superaba los 10 arrateles.

\section{Meteoritos: Características e Historia Terrestre}

\section{Terrassa}

Sinonimias: Barcelona

Peso recuperado. Se desconoce; al parecer no era inferior a las cinco libras $(2 \mathrm{~kg})$ según una fuente, si bien podría ser bastante superior según otra.

Ejemplares. Si bien es de suponer que las piezas recogidas se conservarían durante algún tiempo en razón de su rara procedencia, ningún fragmento sobrevivió para ser estudiado ${ }^{64}$.

Descripción. Es por ello que disponemos tan solo de las descripciones de la época, que lo comparan a escoria de fundición, y que destacan el contraste entre el color negro de la superficie y su interior ceniciento.

Clasificación. Todo parece indicar que se trataba de un meteorito pétreo; probablemente del tipo condrita; es por ello que en los catálogos aparece corrientemente como «stone» 0 «litito».

\section{Sigena}

Sinonimias: Sena, Sena de Aragón, Villanueva de Sigena

Peso recuperado. Se recuperó un fragmento principal de 9 libras y una onza de peso; lo que equivale a 3.186 gramos $^{65}$. Había además otros cinco pequeños fragmentos cuyo peso se desconoce, con lo que puede admitirse un peso total aproximado en torno a los $3,5 \mathrm{~kg}$.

Ejemplar principal. El ejemplar principal — cuyo peso era de $8 \mathrm{lb} 9 \mathrm{oz}$ $(3.051 \mathrm{~g})$ tras algunas extracciones - fue remitido a la Corte y destinado a la

63 R. Southey, «Carta XXI», Letters written during a short residence in Spain and Portugal. Bristol, J. Cottle, 1797, 551 págs., referencia en las págs. 356-357.

${ }_{64}$ Llorca asegura que el propio Chladni estudió un fragmento de este meteorito un siglo después de la caída, lo que resulta harto inverosímil (J. LLORCA, «Les pedres de casa»).

65 Teniendo en cuenta la equivalencia en gramos de la libra empleada en la provincia de Huesca (351 gramos) y su división en 13 onzas. 
colección del Real Gabinete de Ciencias Naturales, hoy Museo Nacional, donde se conserva actualmente.

En 1803, don Pedro Cevallos ordenó a don Manuel Cástor González se entregaran estas piedras a don Luis Proust para que hiciera el correspondiente análisis químico $^{66}$. Según Proust, al salir del Museo (20/05/1803) el ejemplar principal pesaba $6 \mathrm{lb} 10 \mathrm{oz}$, es decir 3.047,5 g ${ }^{67}$ y había además un fragmento de entre 3 y 4 onzas (unos $100 \mathrm{~g}$ ), resto de lo que se llevaron los curiosos $^{68}$, lo que equivale a un peso de $3.147,5 \mathrm{~g}$.

En 21 de abril de 1885 el Museo envió una cantidad indeterminada al doctor Liemachko según consta en un Catálogo manuscrito con tinta y letra de cierto estilo, referente a la de la Colección de Meteoritos ${ }^{69}$. En él se hace referencia a que su peso era entonces de $1.800 \mathrm{~g}$. El mismo ejemplar y peso consta en los catálogos publicados por Gredilla ${ }^{70}$ donde figura con el número 23 . Y con ese mismo peso se da cuenta en el Catálogo de la Colección de Minerales del MNCN fechado el 1 de octubre de 1906. Y lo mismo se relata en el Catálogo manuscrito de $1918^{71}$.

En catálogos posteriores, sin embargo da un peso total de $2.227 \mathrm{~g}$, manteniendo los $1.800 \mathrm{~g}$ que según Gredilla pesaba la pieza principal sin que se mencione la adquisición o donación de nuevas piezas, por lo que cabe considerar que había en el Museo otras muestras además de la principal ${ }^{72}$.

En 1954, Pérez Mateos constató la existencia de tres fragmentos de este meteorito con los siguientes pesos: la pieza principal, de $1.905 \mathrm{~g}$, que se encon-

66 En el catálogo del Museo (vol. 1) consta, con el nº 448, la siguiente documentación: Oficio de don Pedro Cevallos a don Manuel Cástor González para que entregue a don Luis Proust, profesor de química, algunas de las piedras caídas de los aires, en distintas épocas, para analizarlas. Corren unidos: acuse de recibo del 20, y de haber entregado un pequeño cajón con las piedras caídas en Sigena. Oficio del 31 para que se devuelva el sobrante de dicha piedra; comunicación del 23 de agosto informando de la devolución; se recomienda se exponga en la sala de los basaltos una vez publicado el estudio, y oficio aprobando la sugerencia, dado en San Ildefonso el día 26. (Ref «Gabinete», legr. 10, cap. $1 .^{\circ}$ ).

67 Sin duda Proust utilizó la libra castellana o de Ávila, empleada en Madrid y gran parte de España, de 16 onzas y cuyo valor era de $460 \mathrm{~g}$.

68 L. Proust, «Sur une pierre meteorique», págs. 185-205.

69 Libro de entradas y salidas de los objetos de la colección de Geología durante los años de 1877 a 1933, MNCN, Archivo, sign. 0239/03.

70 A. F. Gredilla y Gauna, «Meteorito de Sigena», Estudio sobre los meteoritos, Madrid, Escuela tipográfica del Hospicio, 1892, págs. 103-104; [ «Noticia sobre los meteoritos que existen en algunos Museos y lista de los que hay en el de Madrid»], Anales de la Sociedad Española de Historia Natural, 15 (1886); Actas, págs. 41-45.

71 MNCN, Archivo. El peso de 1.880 g que dio con anterioridad Odón de Buen hacia 1897 en su Historia Natural (Barcelona, Manuel Soler, s/f, tomo I, pág. 136) puede ser debido a un error tipográfico.

72 Faura, Meteoritos; L. Fernández Navarro, «Los meteoritos del Museo de Madrid», Boletín de la Real Sociedad Española de Historia Natural, 23 (1923), págs. 224-233; A. PALuzíE Borreld, «Meteoritos españoles», Urania, 36, 225 (1951), págs. 25-48. Esta suposición se vería apoyada por la existencia en el Archivo del Museo de una relación sin fecha, pero de esa época de la primera mitad del siglo xx, manuscrita en un libro de las Colecciones de Minerales y Meteoritos que en su pág. 26 se notifica con la sigla 686 dos ejemplares de Sigena, aunque no se dan los correspondientes pesos. 
traba cortada en un sector que a su vez fue fragmentado en dos de 21,849 g y 4,449 g respectivamente. Es decir, un total de 1.931,298 g.

En la revisión publicada en 1986, Sena arrojó un peso de $1.708 \mathrm{~g}^{73}$; el mismo peso consta en Martínez Frías y en documentación interna del Museo ${ }^{74}$.

Según consta en una copia sin firmar con fecha de 7 de julio de 1987, y en virtud del entonces Convenio de Cooperación Científica existente entre las universidades de New México y Houston con el MNCN, los investigadores españoles del proyecto que albergaba dicho convenio se llevaron a USA 6,5 g de la muestra n. ${ }^{\circ} 686$ y 19,4 g de la muestra 585, para su estudio ${ }^{75}$.

En el catálogo de Muñoz-Espadas se da como peso total la cantidad de 1.688,6 g, lo que sin duda incluye la pieza principal MET-E-21 (antigua 686), de $1.658 \mathrm{~g}$ y $13 \mathrm{~cm}$ de largo $^{76}$ y dos tubos de polvo MET-E-22 y MET-E-23 de 22,2 y 8,4 g respectivamente ${ }^{77}$.

Ejemplares (tabla 1). Además del ejemplar de Madrid, se conservan algunos fragmentos en museos e instituciones científicas de otros países, los que necesariamente proceden de aquél. El ejemplar «Sena» del Museo Británico fue presentado en 1803 por J. Banks ${ }^{78}$. En tiempos de Faura (1922) los había en los museos de París, Viena, Berlín, Chicago y Londres, con un total de 122,2 gramos. En 1985, según Graham ${ }^{79}$, también en los de Washington, Tempe, Nueva York y Budapest, con un total de $406 \mathrm{~g}^{80}$. El Instituto de Meteoritos de la Universidad de Nuevo México dispone además de una sección delgada ${ }^{81}$.

73 E. A. King, A. San Miguel, I. Casanova, \& K. KeIL, «Inventory of the meteorite collection of the Museo Nacional de Ciencia Naturales, C.S.I.C., Madrid, Spain», Meteoritics, 21, 2 (1986), págs. 193-197.

74 Martínez Frías et al., «Los meteoritos». En un documento mecanografiado del extinto Instituto de Geología ubicado en el MCNC, referido al n. ${ }^{\circ}$ 686, aquí con el nuevo número 472. También en sendos documentos fechados en marzo de 1988 y en 6/03/1989 (MNCN, Archivo; caja 7 [provisional], Meteoritos y Minerales). Poco antes de que se publicara la revisión, el catálogo del British Museum, el más generalmente utilizado por los especialistas de meteoritos había admitido un peso de $1.700 \mathrm{~g}$ (A. L. Graham et al., Catalogue of Meteorites).

75 MNCN, Archivo.

76 M. J. MuÑoz-Espadas et al., «The meteorite collection of the National Museum of Natural Sciences, Madrid, Spain: An updated Catalog», págs. B89-B95. Según la actual Base de Datos de la Colección de Meteoritos del MNCN. La pieza, antigua 686, se encuentra en la sala de exposiciones del Museo.

77 Ambos tubos constan en un listado informático impreso en una máquina matricial (c. 1992).

78 L. FLETCHER, An introduction to the study of Meteorites with a list of the meteorites represented in the collection. Londres, British Museum (Natural History), 1914, 125 págs. En el actual catálogo del British Museum que hemos consultado en la red, no figura esta pieza entre los meteoritos españoles.

79 A. L. Graham et al., Catalogue of Meteorites.

80 Obsérvese que la suma de los 1.708 existentes en el Museo y los $406 \mathrm{~g}(2.214 \mathrm{~g})$ se acerca mucho a la cifra dada por Faura y Fernández Navarro en su época.

81 A. Brearly, Institute of Meteoritics, Meteorite Catalog (1997): http://epswww.unm.edu/metcat/metcat_entry.php 
Tabla 1. Ejemplares conservados ${ }^{82}$

\begin{tabular}{|c|c|c|c|c|}
\hline \multicolumn{3}{|c|}{ Peso (gramos) } & \multirow{2}{*}{ Centro } & \multirow{2}{*}{ Ciudad } \\
\hline $\begin{array}{c}\text { Graham et al, } \\
1985\end{array}$ & Otros & Faura, 1922 & & \\
\hline 1.700 & - & 2.227 & $\begin{array}{l}\text { Museo Nacional de } \\
\text { Ciencias Naturales }\end{array}$ & Madrid \\
\hline 167 & - & - & US National Museum & Washington \\
\hline 101 & $100,1^{*}$ & - & $\begin{array}{l}\text { Center for Meteorite } \\
\text { Studies }\end{array}$ & Tempe \\
\hline 94 & - & - & $\begin{array}{l}\text { Magyar Termeszettudo- } \\
\text { mányi Múzeum }\end{array}$ & Budapest \\
\hline 73 & & $79[58+21]$ & $\begin{array}{l}\text { Museumd'Histoire } \\
\text { Naturelle }\end{array}$ & París \\
\hline 44 & - & - & $\begin{array}{l}\text { American Museum of } \\
\text { Natural History }\end{array}$ & Nueva York \\
\hline 29 & - & $28[4+24]$ & $\begin{array}{l}\text { Naturhistorisches } \\
\text { Museum }\end{array}$ & Viena \\
\hline- & $10^{* * *}$ & 10,50 & $\begin{array}{l}\text { Museum für Natur- } \\
\text { kunde }\end{array}$ & Berlín \\
\hline- & - & 4 & Field Museum & Chicago \\
\hline$\sim 1 \mathrm{~g}$ & - & 0,7 & British Museum & Londres \\
\hline 2.209 & Totales & $2.349,2$ & - & - \\
\hline
\end{tabular}

* Lewis y Moore; ** Hoppe

Peso conservado (tabla 2; figura 4). Comparando el peso obtenido por Proust con el calculado para los tiempos de Faura se observa una pérdida de 693,3 gramos durante el siglo XIX, bien sea por los análisis, extravíos o cualquier otra causa. Durante el siglo xx la pérdida ha sido de 242,9 , teniendo en cuenta los últimos datos del ejemplar de Madrid.

Especialmente sensible ha sido la degradación del ejemplar principal, troceado antes de 1885 (probablemente en tiempos del marqués del Socorro) y siendo canjeados después sus fragmentos por otras muestras con el fin de ampliar la nómina de ejemplares de la colección. Antes de 1922 se habían

82 G. Hoppe, «Gesamtkatalog der in der Deutschen demokratischen Republik vorhandenen meteorite». Wissenchaftliche Zeitschrift der Humboldt-Universität zu Berlin. Math.-Nat., 24 (1975) 521. C. L. LeWIS \& C. B. Moore, Catalog of meteorites in the collection of Arizona State University, including the Nininger meteorite collection. Tempe, Center for Meteorite Studies, 1976. 


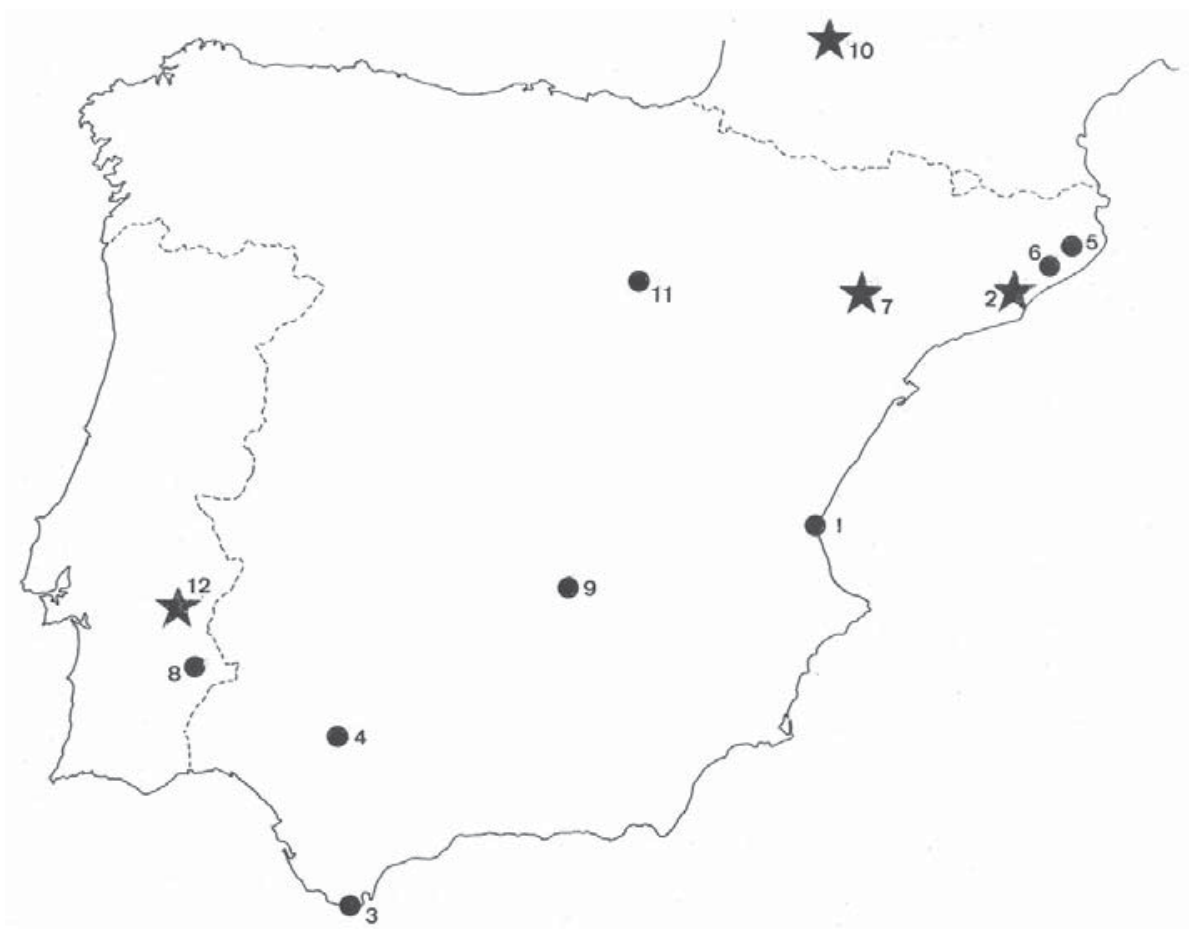

Figura 4. Evolución del peso (kg) del meteorito de Sigena. A. Ejemplar principal (MNCN); B. Otros ejemplares en el MNCN; C. Ejemplares en otros museos.

intercambiado 122,2 g, y actualmente son 522,7 los que se calcula forman parte de otras colecciones. El peso del mayor fragmento resultante de aquel despiece, $1.905 \mathrm{~g}$, se mantuvo constante durante un siglo, pero desde los años cincuenta ha disminuido en $247 \mathrm{~g}$.

En resumen, del peso inicial ingresado en el Museo se ha conservado en éste el 53,6\%; el 16,6\% se encuentra en otros Museos, y el resto $(29,8 \%)$ se ha extraviado o perdido para siempre.

Descripción. El ejemplar del MNCN presenta en su exterior una costra negra y vidriosa muy frágil, lo que no ha hecho posible su total conservación. Su forma es aovada e irregular, semejante a una pirámide, con cúspides muy redondeadas, y en el interior presenta un color gris azulado uniforme que está dado por unos granos ovoides redondeados; entre ellos se encuentran partículas metálicas y sulfuradas, mientras que la parte pétrea tiene estructura oolítica. Su densidad es de $3,46 \mathrm{~g} / \mathrm{cm}^{3}$ (Gredilla, «Meteorito de Sigena»).

Composición química. El análisis químico de este meteorito es uno de los más antiguos y fue realizado por Louis Proust durante su estancia en España (tabla 3). ${ }^{83}$

83 Véanse las obras de Proust ya citadas. Análisis reproducido en A. F. Gredilla y Gauna, «Meteorito de Sigena», págs. 103-104; FAura, 1922; y J. PÉRez Mateos, «Revisión, por análisis espectroquímico, del estudio 
Tabla 2. Evolución del peso total conservado

\begin{tabular}{|c|c|c|c|c|c|c|c|}
\hline & & $\begin{array}{c}1805 \\
\text { (Proust) }\end{array}$ & $\begin{array}{c}1886 \\
\text { (Gredilla) }\end{array}$ & $\begin{array}{c}1922 \\
\text { (Faura) }\end{array}$ & $\begin{array}{c}1954 \\
\text { (Pérez } \\
\text { Mateos) }\end{array}$ & $\begin{array}{c}\text { 1985-86 } \\
(\text { Graham/ } \\
\text { King et al) }\end{array}$ & $\begin{array}{c}2002 \\
(\text { Muñoz } \\
\text { Espadas et al) }\end{array}$ \\
\hline \multirow[t]{3}{*}{ MNCN } & $\begin{array}{l}\text { Ejemplar } \\
\text { principal }\end{array}$ & $3.047,5$ & $\begin{array}{c}1.800 \\
{[1.905]^{*}}\end{array}$ & $\begin{array}{c}1.800 \\
{[1.905]^{*}}\end{array}$ & 1.905 & $\mathrm{~S} / \mathrm{d}$ & {$[1.658,0]^{* *}$} \\
\hline & Otros & 100 & S/d & [427] & 26,3 & $\mathrm{~S} / \mathrm{d}$ & {$[30,6]^{* *}$} \\
\hline & Total & $3.147,5$ & $\mathrm{~S} / \mathrm{d}$ & $\begin{array}{c}2.227 \\
{[2.332]^{*}}\end{array}$ & $1.931,3$ & $\begin{array}{c}1.700 \\
{[1.708]^{*}}\end{array}$ & $1.688,6$ \\
\hline \multirow[t]{3}{*}{$\begin{array}{l}\text { Inter- } \\
\text { cambios }\end{array}$} & Siglo XIX & - & S/d & 122,2 & $\mathrm{~S} / \mathrm{d}$ & $\begin{array}{c}103 \\
{[116,7]^{*}}\end{array}$ & $\mathrm{~S} / \mathrm{d}$ \\
\hline & Siglo Xx & - & $\mathrm{S} / \mathrm{d}$ & - & $\mathrm{S} / \mathrm{d}$ & 406 & $\mathrm{~S} / \mathrm{d}$ \\
\hline & Total & - & $\mathrm{S} / \mathrm{d}$ & 122,2 & $\mathrm{~S} / \mathrm{d}$ & $\begin{array}{c}509 \\
{[522,7]^{*}}\end{array}$ & $\mathrm{~S} / \mathrm{d}$ \\
\hline \multicolumn{2}{|c|}{$\begin{array}{l}\text { Peso total } \\
\text { conservado }\end{array}$} & $3.147,5$ & $\mathrm{~S} / \mathrm{d}$ & $\begin{array}{c}2.349,2 \\
{[2.454,2]^{*}}\end{array}$ & $\mathrm{~S} / \mathrm{d}$ & $\begin{array}{c}2.209 \\
{[2.230,7]^{*}}\end{array}$ & $\mathrm{~S} / \mathrm{d}$ \\
\hline
\end{tabular}

*: cantidad corregida; **: catálogo actual del Museo

Proust encontró, además, indicios de cal y manganeso. Un estudio espectroquímico realizado en 1954 reveló la presencia de: Al, Ca, Co, Cr, Cu, Fe, Mg, $\mathrm{Mn}, \mathrm{Na}, \mathrm{Ni}$, Si y Ti, e indicios de Ga y $\mathrm{Ge}^{84}$.

Mineralogía. Según Gredilla, consta de silicatos de magnesia peridóticos y piroxénicos, a los que se añade una sensible cantidad de alúmina. Entre la parte lapídea, se intercala hierro niquelado, fósforo no definido, troilita y trazas de hierro cromado y grafito. El olivino que contiene fue determinado como tipo $\mathrm{Fa}_{17}$ por Mason ${ }^{85}$.

Clasificación. Gredilla (Anales) lo incluyó en la clase de los esporasidéreos oligosidéreos de la clasificación de Daubrée. Meunier dio a esta roca el nombre específico de Sigenita, haciendo de este meteorito el número 24 de su clasificación taxonómica, si bien considera como parnallitas algunos fragmentos con estructura y densidad $\left(3,3 \mathrm{~g} / \mathrm{cm}^{3}\right)$ diferentes ${ }^{86}$.

de los meteoritos españoles que se conservan en el Museo Nacional de Ciencias Naturales de Madrid», Boletín de la Real Sociedad Española de Historia Natural, 52 (1954), págs. 97-119.

84 Ibid.

85 B. MASON, «Olivine composition in chondrites», Geochimica et Cosmochimica Acta, 27 (1963), págs. 1011-1023.

86 S. Meunier, Guide de la collection de météorites avec le catalogue des chutes représentées au Museum. París, Laboratoire de Géologie du Museum d'Histoire Naturelle, 1909. Faura, Meteoritos. 
Tabla 3. Análisis químico, según Proust (1804)

\begin{tabular}{|l|l|c|}
\hline Parte metálica & $\mathrm{Fe}+\mathrm{Ni}$ & \\
\hline \multirow{5}{*}{ Parte lapídea } & Sulfuro de hierro & 0,12 \\
\cline { 2 - 3 } & Óxido de hierro & 0,05 \\
\cline { 2 - 3 } & Sílice & 0,66 \\
\cline { 2 - 3 } & Magnesia & 0,19 \\
\cline { 2 - 3 } & Total & \\
\hline
\end{tabular}

De acuerdo con las nomenclaturas modernas se le clasifica como condrita tipo H4 por Wasson ${ }^{87}$; una condrita rica en olivino y broncita, H4 (Hoppe, 1975; Lewis y Moore, Catalog of meteorites), o también como una condrita brechoide rica en olivino e hiperstena, $\mathrm{H} 4^{88}$.

\section{Tasquinha}

Sinonimias: San Miguel de Machede, Friexo, Portugal, Évora, Évora Monte.

Peso recuperado. Según la información publicada por la Gazeta de Lisboa, pesaba 10 arrateles, lo que, de acuerdo con las equivalencias que hemos obtenido de esta antigua unidad portuguesa equivaldría a una cantidad en gramos comprendida entre los 4.290 y los 4.590. Por otra parte, en la instrucción del caso publicada por Southey se cifra el peso en 10 libras que, según lo convirtamos a libras inglesas o portuguesas, se transforma respectivamente en 4.536 y $4.890 \mathrm{~g}$; por lo que puede aceptarse un peso aproximado total de $4,5 \mathrm{~kg}$.

Ejemplares. No se ha preservado ningún fragmento del meteorito.

Descripción. En la Gazeta se dice que «en parte era de material calcáreo, y en parte, de una especie de lava». Según el instructor del caso, era de color de plomo y su forma era irregular.

Clasificación. En los registros portugueses se le califica de «pedra», por lo que podría tratarse de un meteorito pétreo o litito, posiblemente una condrita. Según Marvin el color plomizo que refieren los testimonios podría referirse más al tono grisáceo de la corteza, que a su naturaleza metálica ${ }^{89}$; sin embargo para Monteiro ${ }^{90}$ podría tratarse de un siderito.

87 J. T. WAsson, Meteorites, Springer-Verlag (1974), 316 págs.

88 Graham et al., Catalogue of meteoritos; King et aL., «Inventory of the meteorite», Martínez Frías et al., «Los meteoritos».

89 U. Marvin, «The meteorite fall at Evora Monte».

90 F. Monteiro, Meteoros, Meteoritos e Meteoróides [2006?] (página web). 


\section{Antecedentes}

Los primeros catálogos de meteoritos, publicados en 1803 (Drée, Izarn) únicamente registraron en la Península Ibérica el de «Portugal» ${ }^{91}$; también el de Chladni fechado en $1819^{92}$; mientras que en el de 1826 figura además «Barcelona» ${ }^{93}$. En Lithologia metheorica (1854) solamente menciona Balcells «Sena» y «Barbotan», extrayéndolas respectivamente de Proust y Lomet. Greg, en su catálogo de 1861, menciona, además de las cuatro caídas ya conocidas, tres observaciones de bólidos, de los cuales dos desde Barcelona (tabla 4).

Tabla 4. Bólidos y meteoritos de la Península Ibérica catalogados por Greg (1861)

\begin{tabular}{|c|c|l|c|c|c|l|}
\hline Año & $\begin{array}{c}\text { Día } \\
\text { y mes }\end{array}$ & Localidad & $\begin{array}{c}\text { Peso } \\
\text { (lb) }\end{array}$ & $\begin{array}{c}\text { Direc- } \\
\text { ción }\end{array}$ & $\begin{array}{c}\text { Duración; } \\
\text { hora }\end{array}$ & \multicolumn{1}{|c|}{ Observaciones } \\
\hline 1701 & Abril, 6 & $\begin{array}{l}\text { Montjuif [sic], } \\
\text { Barcelona }\end{array}$ & - & $E-W$ & 2 ' 10 PM & $\begin{array}{l}\text { Bólido; se dividió en } \\
\text { varios; muy luminoso? }\end{array}$ \\
\hline 1704 & Dic. 25 & Barcelona & - & SE-NW & 5 PM & $\begin{array}{l}\text { Caída; en Poggendorff, } \\
\text { viii (1826), pág. 46; } \\
\text { varios }\end{array}$ \\
\hline 1704 & Oct. 4 & $\begin{array}{l}\text { Bahía [;] de } \\
\text { Barcelona }\end{array}$ & - & $\begin{array}{l}\text { Descen- } \\
\text { dente }\end{array}$ & - & Bólido \\
\hline 1723 & Ene. 6 & Portugal & - & - & - & Bólido \\
\hline 1773 & Nov. 27 & $\begin{array}{l}\text { Sigena, } \\
\text { Aragón }\end{array}$ & 9 & - & Mediodía & $\begin{array}{l}\text { Caída diurna; peso } \\
\text { espec. 3,63 }\end{array}$ \\
\hline 1790 & Julio 24 & $\begin{array}{l}\text { Barbotan, } \\
\text { Landes, } \\
\text { Bordeaux }\end{array}$ & $20+10$ & S-N & 9 PM & $\begin{array}{l}\text { Caída múltiple; peso } \\
\text { espec. 3,62. Rochefort }\end{array}$ \\
\hline 1796 & Feb. 19 & $\begin{array}{l}\text { Friexo, } \\
\text { Portugal }\end{array}$ & 10 & - & - & $\begin{array}{l}\text { Caída; cerca de Evora; } \\
\text { río Friexo }\end{array}$ \\
\hline
\end{tabular}

En cursiva, los mencionados en el suplemento al catálogo.

91 Catálogo de Drée, publicado por Izarn (1803), en U. B. MARvin, «Ernst Florens Friedrich Chladni (1756-1827)», págs. 545-588. En él Barbotan aparece por duplicado: como «Agen» con la fecha correcta, y «Barbotan» con fecha de julio de 1789.

92 Figuraba como «Tasquinha», según Ben-Saude, 1888.

93 Es incierto que, como aseguran algunos, Chladni estudiara un fragmento de ese meteorito a los cien años de su caída. No hay duda, en cambio, de que tuvo conocimiento de él, muy probablemente a través de la noticia publicada en la historia de Feliu de la Peña. 
Los catálogos ibéricos de Faura, Gómez de Llarena y Paluzie dan noticias del bólido «Barcelona», así como de las caídas de «Villanueva de Sigena» y «Tasquinha»; ésta con alguna inexactitud en la fecha94. Martín Escorza añade a los meteoritos españoles los de «Los Rábanos», considerados como sendas caídas ${ }^{95}$.

\section{Resultados}

La recopilación efectuada por nosotros permite elaborar un nuevo catálogo de observaciones y caídas. Para ello se han seleccionado únicamente las observaciones debidamente contrastadas por otros observadores; así como aquellas informaciones que, siendo únicas, merecen credibilidad, ya sea por lo inequívoco de la descripción o por la solvencia del observador; los demás testimonios, dudosos o falsos, han sido descartados. De este modo se ha obtenido la tabla 5 , en la que figuran las tres caídas ya conocidas en el solar ibérico, más 10 bólidos observados; la mayoría durante la segunda mitad del siglo.

\section{Tabla 5. Nuevo catálogo de bólidos observados y meteoritos caídos en la Península Ibérica}

\begin{tabular}{|c|c|c|l|c|c|l|}
\hline Año & Mes; día & Hora & \multicolumn{1}{|c|}{ Localidad } & $\begin{array}{c}\text { Trayec- } \\
\text { toria }\end{array}$ & $\begin{array}{c}\text { Peso recu- } \\
\text { perado (kg.) }\end{array}$ & \multicolumn{1}{|c|}{ Observaciones } \\
\hline 1701 & S/d & S/d & Valencia & S/d & - & $\begin{array}{l}\text { Bólido visto en Valencia y otros } \\
\text { puntos }\end{array}$ \\
\hline 1704 & Dic. 25 & 17 & Terrassa & SW-NE & $>2$ & $\begin{array}{l}\text { Caída; bólido muy aparatoso, } \\
\text { visto en gran parte de Cataluña }\end{array}$ \\
\hline 1715 & Feb. 18 & 06 & Tarifa & S-N & - & Bólido; única observación \\
\hline 1755 & Jul. 29 & 20 & $\begin{array}{l}\text { Provincias de } \\
\text { Cádiz y Sevilla }\end{array}$ & S-N & - & Bólido visto en 4 localidades \\
\hline 1755 & Nov. 22 & 19 & La Selva (Girona) & S-N & - & Bólido visto en 2 localidades \\
\hline 1766 & Jun. 2 & $21 \mathrm{~h} 45$ & Cataluña & SW-NE & - & $\begin{array}{l}\text { Bólido visto en gran parte de } \\
\text { Cataluña }\end{array}$ \\
\hline 1773 & Nov. 17 & $12 \mathrm{~h} 30$ & Sigena (Huesca) & NW-SE & 3,5 & Caída; sin datos del bólido \\
\hline 1786 & Abr. 11 & $19 \mathrm{~h} 30$ & Moura (Beja) & NE-SW & - & Bólido; única observación \\
\hline
\end{tabular}

94 Faura (Meteoritos) introdujo un error en la fecha de la caída de Tasquinha (día 10 en lugar de 19), que se repite en los catálogos de Gómez de Llarena (J. Gómez de Llarena, «Meteor-Fälle auf der Pyrenäen-Halbinsel», Natur und Volk, 68.1 (1938), págs. 8-15) y Paluzie («Meteoritos españoles»). Otros errores deslizados en los cuadros sinópticos del catálogo de Faura son evidentes errores de imprenta: Tarquinha por Tasquinha; 2.277 por 2.227 en el peso del ejemplar de Sigena del MNCN.

95 C. Martín Escorza, «Fenómenos meteoríticos ocurridos en España». 


\begin{tabular}{|c|c|c|l|c|c|l|}
\hline Año & Mes; día & Hora & \multicolumn{1}{|c|}{ Localidad } & $\begin{array}{c}\text { Trayec- } \\
\text { toria }\end{array}$ & $\begin{array}{c}\text { Peso recu- } \\
\text { perado (kg.) }\end{array}$ & \multicolumn{1}{|c|}{ Observaciones } \\
\hline 1788 & Mayo 18 & 18 & $\begin{array}{l}\text { La Solana (Ciudad } \\
\text { Real) }\end{array}$ & S/d & - & Bólido; única observación \\
\hline 1790 & Jul. 24 & 21 & Barbotan (Francia) & SW-NE & {$[15]$} & $\begin{array}{l}\text { Caída; bólido observado desde } \\
\text { Barcelona }\end{array}$ \\
\hline 1791 & Oct. 26 & S/d & Los Rábanos (Soria) & S/d & - & Bólido; única observación \\
\hline 1795 & Ago. 19 & S/d & $\begin{array}{l}\text { Los Rábanos } \\
\text { (Soria) }\end{array}$ & S/d & - & Bólido; única observación \\
\hline 1796 & Feb. 19 & 14 & Tasquinha(Alentejo) & S/d & 4,5 & Caída; sin datos del bólido \\
\hline
\end{tabular}

De un total de 33 casos estudiados se han inventariado 13, esto es el $39,4 \%$ del total; un porcentaje que es distinto según se trate de caídas (tres sobre cinco supuestas) o de bólidos (aproximadamente tres de cada diez). Por término medio ello significa una observación (cierta o dudosa) cada tres años; un caso comprobable cada 7,7 años y una caída cada 33 años. En términos territoriales, 21 bólidos por millón de $\mathrm{km}^{2}$, de los cuales 5 con recuperación de material (tabla 6).

\section{Tabla 6. Valores-promedio}

\begin{tabular}{|l|c|c|c|}
\hline \multicolumn{1}{|c|}{ Casos } & Valor absoluto & $\begin{array}{c}\text { Período de retorno } \\
\text { (años) }\end{array}$ & $\begin{array}{c}\text { Densidad (casos } \\
\left.\text { por } \mathbf{1 0}^{\mathbf{6}} \mathbf{k m}^{2}\right)\end{array}$ \\
\hline Estudiados & 33 & 3 & 55 \\
\hline Comprobados & 13 & 7,7 & 21 \\
\hline Caídas & 3 & 33 & 5 \\
\hline
\end{tabular}

En cuanto a la proporción de caídas sobre el total de casos estudiados es de uno a once; mientras que para los casos catalogados baja a 1:4,3; lo que se acerca a los 1:5,3 que se obtienen de la parte correspondiente al siglo XVIII del catálogo de Greg. Tomando como referencia ese mismo catálogo, tendríamos que los eventos catalogados en la Península representarían el 5,4\% del total mundial: el 6,6\% de las caídas y el 4,6\% de los bólidos.

\section{Discusión}

La distribución espacial de los casos no es en absoluto homogénea, pues de algunas regiones se dispone de mayor información que de otras (tabla 7; figura 5). 


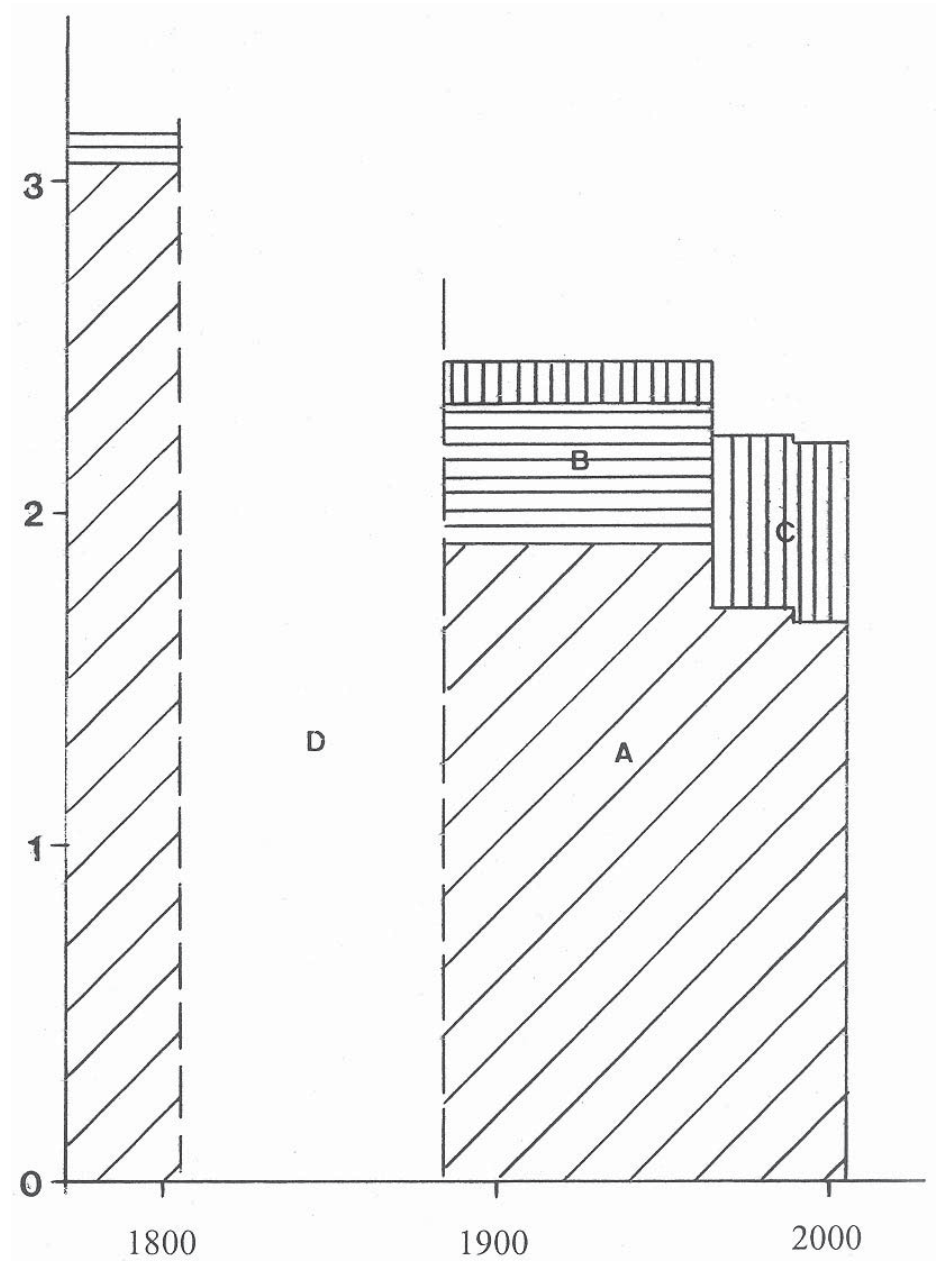

Figura 5. Distribución territorial de los fenómenos catalogados: Estrellas: puntos de caída de meteoritos; Círculos: bólidos observados.1, Valencia (1701); 2, Terrassa (25/12/1704); 3, Tarifa (18/02/1715); 4, Sevilla (29/07/1755); 5, La Selva (22/11/1755); 6, Cataluña (2/06/1766); 7, Sigena (17/11/1773); 8, Moura (11/04/1786); 9, La Solana (18/05/1788); 10, Barbotan (24/07/1790); 11, Los Rábanos (26/10/1791 y 19/08/1795); 12, Tasquinha (19/02/1796).

Destaca la gran cantidad de información procedente de Cataluña —más del 50\% de los casos estudiados, lo que cabe atribuir en parte a la influencia del meteorito de 1704, pero también a un mejor conocimiento documental-y su práctica ausencia en Galicia y la cornisa cantábrica; mientras que en el resto el número de casos estudiados (entre uno y tres por región) no guarda relación con la superficie territorial. El número de casos inventariados refleja esta desigualdad, pero no en la misma proporción, debido a que cuando hay información sobre pocos casos, ésta suele ser relevante. 
Tabla 7. Distribución espacial

\begin{tabular}{|l|c|c|}
\hline \multicolumn{1}{|c|}{ Área geográfica } & Casos estudiados & Casos inventariados \\
\hline Cataluña & 18 & $4^{*}$ \\
\hline Portugal & 5 & $3^{*}$ \\
\hline Andalucía & 3 & 1 \\
\hline Castilla y León & 2 & 2 \\
\hline Castilla-La Mancha & 2 & 1 \\
\hline Aragón & 1 & $1^{*}$ \\
\hline País Valenciano & 1 & 1 \\
\hline Extremadura & 1 & - \\
\hline Total & 33 & 13 \\
\hline
\end{tabular}

* (el asterisco señala una caída)

En el tiempo, se aprecia una mayor actividad aparente en la primera década del siglo, en la de los años cincuenta, y en las dos últimas décadas (tabla 8). Las dos primeras pueden explicarse por la influencia de la caída de 1704 y por la información generada alrededor del terremoto de Lisboa; para la última podría invocarse la mayor cantidad de información original producida y/o conservada.

\section{Tabla 8. Distribución temporal}

\begin{tabular}{|c|c|c|}
\hline Década & Casos estudiados & Casos catalogados \\
\hline $1700-1709$ & 9 & $2^{*}$ \\
\hline $1710-1719$ & 1 & 1 \\
\hline $1720-1729$ & 1 & - \\
\hline $1730-1739$ & - & - \\
\hline $1740-1749$ & 1 & - \\
\hline $1750-1759$ & 6 & 2 \\
\hline $1760-1769$ & 2 & 1 \\
\hline $1770-1779$ & 1 & $1^{*}$ \\
\hline $1780-1789$ & 5 & 2 \\
\hline $1790-1799$ & 7 & $4^{*}$ \\
\hline Total & $\mathbf{3 3}$ & $\mathbf{1 3}$ \\
\hline
\end{tabular}




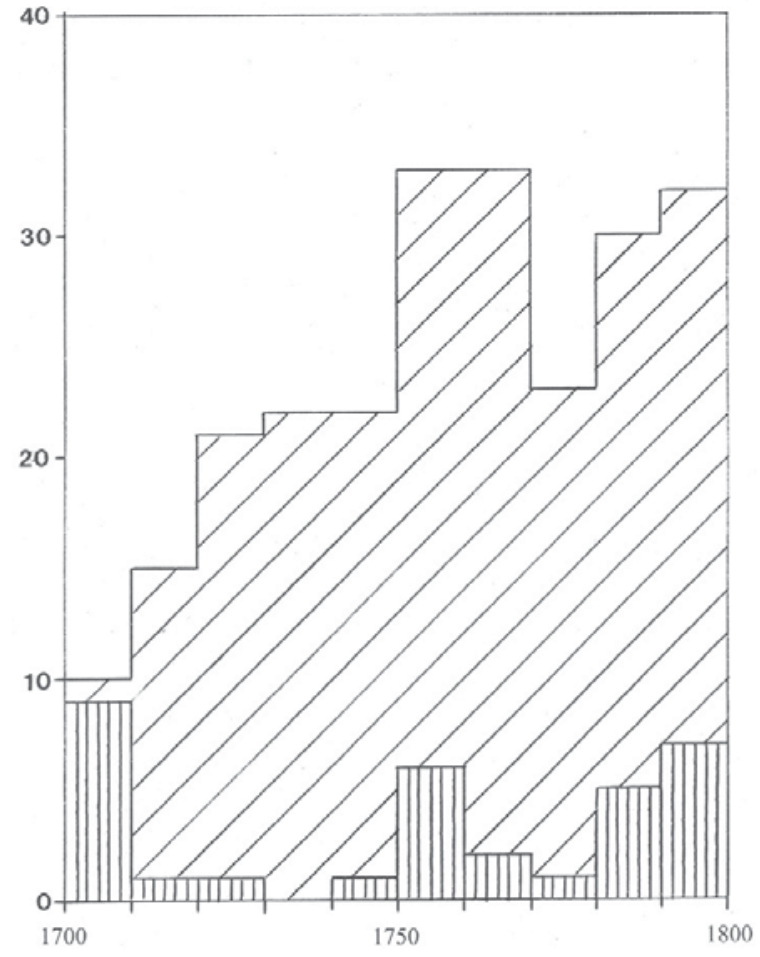

Figura 6. Comparación de la distribución temporal de los casos estudiados con los registrados en el catálogo de Greg.

Comparando los tres máximos obtenidos con el catálogo de Greg (tabla 9, figura 6) se aprecia en general una buena correlación, con excepción del primer máximo, que parece corresponder a causas locales.

Tabla 9. Actividad meteorítica conocida a nivel global

\begin{tabular}{|c|c|c|c|}
\hline Década & Meteoritos & Bólidos & Total \\
\hline $1700-1709$ & 3 & 7 & 10 \\
\hline $1710-1719$ & 2 & 13 & 15 \\
\hline $1720-1729$ & 4 & 17 & 21 \\
\hline $1730-1739$ & 3 & 19 & 22 \\
\hline $1740-1749$ & 3 & 19 & 22 \\
\hline $1750-1759$ & 6 & 27 & 33 \\
\hline $1760-1769$ & 3 & 30 & 33 \\
\hline $1770-1779$ & 7 & 16 & 23 \\
\hline $1780-1789$ & 5 & 25 & 30 \\
\hline $1790-1799$ & 9 & 23 & 32 \\
\hline Total & 45 & 196 & 241 \\
\hline
\end{tabular}

Fuente: Catálogo de Greg, 1861. 


\section{Percepción e Interpretación}

\section{Avisos divinos}

A principios de siglo la ciencia estaba muy lejos de interpretar correctamente la sorprendente aparición de los bólidos y la caída de materiales. La visión del bólido de 1704 sobre Barcelona, fenómeno sin precedentes conocidos, causó desconcierto, espanto y horror; su recuerdo permaneció imborrable en la mente de los testigos oculares (el dibujo realizado por Joseph Bolló es 13 años posterior al suceso). Siguiendo la tradición que desde tiempo inmemorial el vulgo aplicaba a la aparición de los cometas, se le atribuyó carácter premonitorio; su coincidencia con el día de Navidad y la semejanza de su estela con la cruz oblicua de Santa Eulalia reforzaron el supuesto carácter de aviso divino.

En realidad, el carácter positivo o negativo de la predicción varió de acuerdo con las circunstancias del momento: mientras las armas de los aliados parecían ganar la partida se le atribuyó el anuncio del nuevo rey y de la victoria, en un intento por instrumentalizar el caso con fines propagandísticos; por el contrario, cuando se torció el curso de la guerra, Cataluña fue abandonada a su suerte, sometida y represaliada, se la tuvo por anuncio de las calamidades ${ }^{96}$. No obstante, los documentos de la época no dudaron en asociar la visión del bólido con las piedras caídas en Terrassa; algo por demás evidente para el observador cercano.

Feliu de la Peña presenta en 1709 un catálogo de cinco supuestas observaciones ocurridas entre 1701 y 1706, interpretadas como advertencias de sucesos importantes en el contexto de la guerra de Sucesión; más adelante reducidas a dos por su epígono Castellví, quien en 1733 escribía aún:

Estos presagios dio la naturaleza, instruida de la Providencia; y aunque todos son vulgares fenómenos, amenaza Dios con ellos para correr a la enmienda de los vicios. Esto dio asuntos a varias interpretaciones, según lo vario de los efectos. Difundida la noticia en Europa, muchos lo consideraron presagio de lastimosos sucesos. En España se temió común infortunio; en Cataluña, atemorizó a los más; admiró a todos. A pocos les pareció preludio de felicidades. Los más reflexivos discurrieron vaticinio de sangrienta guerra en los límites de la Corona de Aragón, y en particular en Cataluña, y que la España toda sería sangriento teatro de infelicidades. Todo el vulgo lo tuvo a fatal agüero ${ }^{97}$.

96 E. Aragonès, «Senyal de foc al cel».

97 F. Castellví, Narraciones históricas desde el año 1700 hasta el año 1725, vol, I, pág. 466. 


\section{Exhalaciones terrestres}

Tosca, en su Compendio Mathematico publicado en 1713, designa a los meteoros aéreos muy resplandecientes y de muy breve duración como Llama o Antorcha y los supone engendrados en el aire por supuestas exhalaciones sulfúreas pingües y por materia depurada, encendida. En cuanto a los rayos, duda que acarreen piedras, pero no lo descarta del todo:

Sienten algunos, que tal vez llevan consigo una piedra muy solida, y firme, que los Philosophos llaman Telum; pero esto lo tengo por muy dudoso, porque la sobredicha piedra hiriendo los edificios havia de hacer el efecto de una vala de Artilleria de mediana grandeza: y en los heridos de los Rayos se avia de hallar herida de competente magnitud á dicha piedra; lo cual es contra la experiencia [...] si alguna vez acompaña al rayo dicha piedra, ésta se formaría en la nube por union de las particulas térreas y nitrosas, mezcladas con otras bituminosas, y apretadas por los vientos opuestos y fuertes, convertidos en piedra por accion de la llama del rayo; la cual se debe tambien a las exhalaciones terrestres condensadas en la media region del aire ${ }^{98}$.

En 1736 el padre Feijoo atribuyó a las exhalaciones terrestres la caída de meteoritos observada en la India:

El ímpetu de las exhalaciones es à veces tan grande, que puede levantar cuerpos mayores, que cualquiera semilla. En las Observaciones Physico-Medicas de Alemania de el año de 1685, se refiere, que en la India Oriental, tal vez en los nublados, caen piedras metalicas, y que Rumphio, Historiador, de la Compañía Holandesa de el Oriente, embiò de aquel pais à Mentzelio, Medico del elector de Brandemburg, una espatula de bronce, que pesava cerca de once onzas, que decia haber caido de las Nubes en una tempestad: Sit penes illum fides ${ }^{99}$.

Por otra parte, descartó que las llamadas piedras de rayo tuvieran en realidad el origen que el vulgo les atribuía:

Los que están en la común aprensión de que en el Rayo baja una piedra puntiaguda, y cortada a muchas caras, a quien por esto llaman Piedra del Rayo, fácilmente concebirán, que el Rayo es pesado. Pero de esta común aprensión se

98 T. V. Tosca, «Tratado XXII Phisico-Mathematico de los Metheoros terrestres, aqueos, aereos, y ethereos».

99 Feijoo, TCU, t. VII (1736), d. II «Peregrinaciones de la Naturaleza», § VIII.32. 
ríen los mejores Filósofos. No hay más razón para atribuir un origen, digámoslo así misterioso a las piedras de esta determinada figura, que a las de figura oval, cilíndrica, prismática, cúbica, y esférica, que se encuentran en muchas partes. ¿Y quién no ve, que bajando el Rayo con tanto ímpetu, esa piedra se había de hacer pedazos, o por lo menos deformarse mucho al herir en cualquiera cuerpo? [...] ¿No es quimera, que después de herir en un edificio, en un árbol, y aún en la tierra más esponjosa quedase, no sólo entera, sino tan tersa, y tan bien formada su cúspide, sus caras, sus esquinas? [...] Finalmente, supóngase en el Rayo el peso que se quisiere, nunca puede en virtud de él bajar con la celeridad con que se dice baja, ni aún con la décima parte de ella. El P. Dechales con repetidos experimentos halló, que una piedra dejada caer de lo alto, consume tres minutos segundos en bajar ciento y veinte y tres pies. ¿Cómo se pretende, que el rayo en un minuto segundo (porque tanta celeridad poco más, o menos se le atribuye) descienda de la nube, distante seiscientos pies o más, a la Tierra? ${ }^{100}$.

Después del destructor terremoto de Lisboa se prestó especial atención a las señales que podrían haberlo anunciado, entre ellas los denominados «globos de fuego» que algunos declararon haber observado en días anteriores y posteriores en el curso de la investigación oficial impulsada por los gobiernos español y portugués sobre el célebre sismo ${ }^{101}$. En la época se creía que los terremotos se producían por la explosión de gases existentes en hipotéticas oquedades del subsuelo; lo que llevaba a suponer que se emitían a la atmósfera exhalaciones incandescentes.

El 4 de junio de 1766 el académico Desvalls ${ }^{102}$ intentó explicar el origen del bólido observado en Cataluña ante la Conferencia Phisico-Mathematica Experimental de Barcelona, reunida a instancias del marqués de la Mina. Dicho autor, de acuerdo con sus contemporáneos, consideró el fenómeno como un «globo de fuego», categoría que incluía tanto los menores (estrellas fugaces) como los mayores; en su opinión se trataba del mismo fenómeno; entre unos y otros no habría otra diferencia que la distancia que nos separaba de ellos. Atribuyó el meteoro a las evaporaciones resultantes de los terremotos, y su explosión a la combinación de supuestas substancias bituminosas combinadas con el ácido universal o vitriólico existente en la atmósfera en presencia de vapor de agua. De su duración dedujo que en su composición intervino una porción de vapores

100 FEIJoo, TCU, t. VIII (1739), d. IX «Patria del Rayo», §. III.7.

101 Pereira de Sousa, O terremoto do $1^{\circ}$ de Novembro de 1755; Martínez Solares, Los efectos en España del terremoto de Lisboa.

102 Juan Antonio Desvalls y d'Ardena [1740-1820], marqués de Alfarràs y de Llupià, prohombre barcelonés, fue uno de los fundadores en 1764 y el principal impulsor de la Conferencia, predecesora de la Academia de Ciencias y Artes de la ciudad. 
bituminosos y pingües; del color blanco de su cola, la presencia del alcanfor; descartó la presencia de nitro en la atmósfera, pero admitió la del ácido vitriólico. La mutua atracción mantendría unidos dichos ingredientes apenas se elevaron por la acción del fuego subterráneo, y el calor del sol haría aumentar su volumen, con la consiguiente disminución del peso específico. La inflamación sobrevendría por excitación eléctrica o por efervescencia; el impulso podría depender de causas externas (viento) o de la reacción opuesta a la inflamación, como los fuegos artificiales; también podría haber ocurrido que se inflamara una línea de vapores, sin ninguna necesidad de impulso ${ }^{103}$.

La caída de Sigena en 1773 motivó algunas consideraciones filosóficas a cargo del médico de Tarazona Antonio Aguirre ${ }^{104}$, a las que por desgracia no nos ha sido posible acceder. Por fortuna, lo insólito del acontecimiento desencadenó la primera investigación oficial de un caso semejante: el capitán general de Aragón, Antonio Manso, con buen criterio recabó información de las autoridades locales y solicitó la pieza caída, lo que fue debidamente cumplimentado y remitido a la Corte en febrero del siguiente año. El propio capitán general manifestó por escrito su opinión sobre el fenómeno; aunque no se pronuncia sobre el mecanismo que lo produjo, descarta, de acuerdo con las ideas de su tiempo, cualquier procedencia que no sea la terrestre:

[...] dejo a los sabios que discurran si la piedra fue erupción de la tierra que la fermentación le dio impulso para elevarse hasta lo perceptible de la esfera terrestre, y que su gravedad la precipitó al paraje en que se vio caer; (o) si algún torbellino levantó porción de materias que se unieron por la recíproca atracción que tendrían para juntarse, formando la piedra, y que cayó esta de la nube en que tuvo efecto esta operación, o que cayendo alguna exhalación mayor que las regulase, hallase la piedra en el territorio en que terminó su actividad, le comunicase su calor, la tostase (alusión a al existencia de la costra negra) en su superficie y dejase el olor de sus materias que se notó (fétido según el testimonio de los testigos). Y solo digo para mí, que el suceso cuando no sea positivamente singular, no es común ${ }^{105}$.

\section{¿Electricidad o vulcanismo?}

A raíz de la observación del bólido de La Solana (18 de mayo de 1788), comunicada por Alfonso Tabares, Diego Peñalosa respondió lo siguiente:

103 J. A. Desvalls, apud. J. Iglésies, «La Real Academia de Ciencias y Artes en el siglo XVIII», p.d. $371-372$.

104 Latassa, Biblioteca Nueva.

105 A. Manso: carta a Manuel de Roda, fechada en Zaragoza el 5/02/1774; publicada en Jimeno, «Noticias históricas». 
Hoy se recurre por todos á la electricidad en estas materias, y parecerá más bien decir que la nube atraxo aquella porción de masa electrica, que suele afectar agregarse á mayor porcion de su especie, que en la insinuada nube residía, no siendo necesario que el fluido electrico se halle rodeado de vapores, ó nieblas visibles, pues fuera de ellas hay en este tiempo especialmente grandes cantidades sulfúreo-nitrosas, oleosas, \&C. [...] El humo que V.S. dice se vió en el origen del rayo, sería residuo de la inflamación sulfúrea, pues esto es cierto, factible sin recurso á la electrización, y esta tampoco es excluída de ello ${ }^{106}$.

Entre 1788 y 1790 el doctor Francisco Salvà ${ }^{107}$ publica en el Memorial literario diversas observaciones realizadas desde Barcelona, notando que algunos autores atribuyen estos fenómenos a causas eléctricas.

La caída de Barbotan (1790) tuvo eco en nuestro país, en el tomo 21 del siempre atento Memorial literario; se atribuyó en principio a una supuesta actividad volcánica:

En el 28 [sic] del mismo mes de julio (según las Gacetas), en los Pirineos de la parte de Armañac, se avistó por la noche un resplandor muy claro, que iluminó todo aquel horizonte por espacio de 6 minutos, y era un volcán que entre sus llamas había eructado una lluvia de materiales como piedras, negras en lo exterior y encarnadas en lo interior, parecidas en su composición á limaduras de varios metales ${ }^{108}$.

En el vecino país, Bertholon publicó los primeros informes y St. Amans recibió una deposición ante notario signada por un alcalde y sus consistorio, estableciendo que por lo menos 300 ciudadanos habían observado la caída, lo que no admitió más que como prueba de la credulidad de la gente del campo, y convenció a Bertholon (1791) de que el fenómeno era físicamente imposible. En 1796, Baudin publicó una descripción detallada de la caída que había obser-

106 D. Peñalosa, [Respuesta a una carta de A. Tabares] Memorial literario, vol. 14 (1788), pág. 667-670.

107 Francisco Salvà y Campillo [1751-1828], ilustre médico, científico e inventor barcelonés. Se graduó en Huesca y doctoró en Tolosa de Languedoc; fue académico de medicina (1773) y de ciencias (1786) y catedrático de medicina práctica (1801). Fue uno de los primeros inoculadores de la viruela en España. Además de su profesión, cultivó la meteorología, la física y la química: sus observaciones meteorológicas, mantenidas a lo largo de más de 40 años, eran comunicadas al Diario de Barcelona y al Memorial literario; hizo algunas pruebas aerostáticas poco después de Montgolfier, y fue precursor de la telegrafía sin hilos. Véase sobre esta figura: S. Riera TuÈBols, Ciència i tècnica a la Il-lustració: Francesc Salvà i Campillo (1751-1828), Barcelona, la Magrana (Col. «Els orígens», n 14), 1985; también: J. Sánchez MiñAnA, «La colaboración del doctor Salvà i Campillo con el Memorial literario de Madrid (1786-1790): Una ventana sobre el paisaje científico y sus figuras en la Cataluña de finales del XvıII», Quaderns d'Història de l'enginyeria, 4 (2000), págs. 184-230.

108 Memorial literario, 21 (oct. 1790), pág. 370. 
vado; pero los editores advirtieron en nota al pie que el autor debería haber sido más filosófico para dudar de la caída de piedras, que sólo el aturdimiento de los testigos por la luz y el sonido del meteoro les podía hacer creer. El propio Chladni insertó una traducción del informe de Bodin en el segundo volumen del Philosophical Magazine ${ }^{109}$. También se atribuyó origen volcánico a la caída de Tasquinha por su aspecto de lava en la prensa contemporánea ${ }^{110}$.

\section{Origen incierto}

Southey no hace referencia en ningún momento al posible origen de la piedra caída del cielo en 1796 en Portugal. El caso es que en la Inglaterra de la época había por entonces una gran expectación alrededor de este tipo de fenómenos: en 1796 Edward King publicó el primer tratado aparecido en lengua inglesa donde, además de comparar ambos meteoritos entre sí y con el de Cornualles de 20/10/1791, difundió el texto inaugural de Chladni ${ }^{111}$; y Bingley publicó en el Gentlemen's Magazine de agosto un informe sobre la caída de Pettiswood de 1779. En febrero de 1797, Hamilton divulgó la caída de Siena (16 de junio de 1794) en las Philosophical Transactions of the Royal Society. Sin embargo, según Marvin ${ }^{112}$, Southey no estaba al corriente de tales caídas y adoptó una actitud no comprometida; pero su informe fue oportuno y aportó una nueva evidencia de las piedras caídas del cielo.

Hay que tener en cuenta que, si bien hacía dos años Chladni había propuesto la hipótesis genética que con el tiempo sería aceptada universalmente, la comunidad científica de su tiempo estaba muy lejos de admitir el origen extraterrestre de los aerolitos ${ }^{113}$. Ello queda perfectamente reflejado en el catálogo de Izard de $1803^{114}$ donde las diversas teorías genéticas, entre las cuales la de Chladni, aparecen citadas en pie de igualdad.

109 U. B. Marvin, «Ernst Florens Friedrich Chladni (1756-1827)», págs. 545-588.

110 Gazeta de Lisboa, 22/03/1796.

111 E. F. F. Chladni, Über den Ursprung der von Pallas Gefundenen und anderer ihr ähnlicher Eisenmassen, und über einige damit in Verbindung stehende Naturerscheinungen (Riga, J.F. Hartknoch, 1794, 63 págs). Actualmente esta obra está considerada como el texto fundacional de los estudios meteoríticos. En ella emite la hipótesis de que existen en los espacios celestes ciertas agrupaciones de materia densa independientes de los grandes cuerpos planetarios; se mueven hasta llegar a las proximidades de otros cuerpos que por su atracción superior determinan su caída. Por su velocidad, y violento rozamiento desprenden electricidad y calor, lo que produce su estallido.

112 U. B. Marvin, «Ernst Florens Friedrich Chladni (1756-1827)», págs. 545-588.

113 Entre los primeros partidarios de Chladni habría que situar al mineralogista español Andrés Manuel del Río [1765-1849], quien en sus Elementos de Orictognosia (México, 1795), al hablar de las masas de hierro encontradas por Rubín de Celis, se hace eco de los argumentos del físico alemán para concluir: «Hechos del día parecen confirmar todavía más la teórica de Chladni» (pág. 42).

114 U. B. Marvin, «Ernst Florens Friedrich Chladni (1756-1827)», págs. 545-588. 
En el Diccionario Universal de Física de Brisson ${ }^{115}$, se define Globo de Fuego como: «Meteoro inflamado. Fuego de la naturaleza de los relámpagos, que aparece en el aire en forma de Globo; y cuya rapidez de movimiento le ocasiona la apariencia de una cola».

En 1801 apareció en el Semanario de Agricultura un artículo sobre «fragmentos de piedras que han caído de las nubes en distintas partes», sin que el autor se pronunciara sobre su origen ${ }^{116}$.

Proust, que dio a conocer al mundo la caída de Sigena, no tenía ninguna duda de que se trataba de materia terrestre proyectada al espacio, puesto que en su opinión los elementos que componían los aerolitos no podían crearse ni conservarse disueltos en la atmósfera; por ello supuso que debían proceder de la tierra que rodeaba a los polos, de la que habrían sido arrancados por alguna causa violenta ${ }^{117}$.

Ignacio Savall ${ }^{118}$, en un discurso inaugural de la cátedra de química establecida bajo la dirección de la Real Sociedad Aragonesa de Amigos del País, leído el 16 de enero de 1818, se ocupó también de la formación de los meteoritos entre otros temas de química, en un manuscrito cuyo paradero desconocemos ${ }^{119}$.

Por otra parte, consta que el 26 de mayo de 1819 el académico Ramon Muns i Serinyà ${ }^{120}$ leyó ante la Academia de Ciencias de Barcelona una Memoria sobre la verdadera existencia y causas físicas de los aerolitos ó sean piedras caídas del cielo. En el archivo de dicha corporación se conserva un manuscrito sin fecha que bien pudiera ser obra de Muns: en él se descartan sucesivamente las hipótesis de Chladni (materia densa procedente del espacio), Izarn (gases atmosféricos), Patrin (fluidos gaseosos procedentes de la tierra), Proust (material terrestre proyectado al espacio) y Lagrange (procedencia de volcanes lunares), además de las del origen volcánico terrestre y de los fragmentos planetarios; descartada la presencia exterior con el argumento que las infinitas caídas habrían alterado

115 Madrid, Imprenta Real, 1800, tomo V.

116 «Extracto de la segunda carta de Pictet, fecha en Edimburgo a 18 de julio de 1801», Semanario de Agrigultura y Artes dirigido a los párrocos, 10, págs. 359-368.

117 A. Libes, «De las aerolitas o piedras caídas del cielo», Tratado de física completo y elemental presentado bajo un nuevo orden con los descubrimientos modernos; 3. ${ }^{\mathrm{a}}$ ed. Barcelona, A. Brusi, 1829, vol. 3, págs. 288-296.

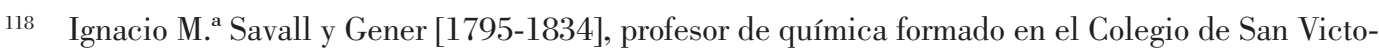
riano de Barcelona; académico de la de Ciencias de la ciudad en 1816 y de la de Zaragoza en 1831, ciudad en donde fue catedrático desde diciembre de 1817.

119 Maffei y Rúa, Bibliografía mineral.

120 Muns era abogado, formado en la Junta de Comercio; estudió también economía, física y química y fue miembro de la Sociedad Filomática. Ocupó sucesivamente los cargos de oficial (1820) y secretario (1822) de la Diputación Provincial de Cataluña, secretario del Ayuntamiento de Barcelona (1833) y organizador del Archivo Municipal. 
el período de rotación del globo, propone que la electricidad acumulada en los polos, junto con la materia fundida o gaseosa, formaría una segunda atmósfera a 30-40 leguas de la Tierra, la cual contendría los principios formadores de los aerolitos $^{121}$.

También el tratado de física de A. Libes, que fue objeto de tres ediciones en nuestro país entre 1819 y 1827, descarta la hipótesis de Chladni, que sería ingeniosa y plausible si, según el autor, no se opusiera a las circunstancias que realmente acompañan el fenómeno, porque la explosión se produce después y no antes de la extinción de su luminosidad. En opinión de Libes, todas las teorías emitidas hasta entonces no eran más que conjeturas necesitadas de nuevas observaciones $^{122}$.

\section{Aceptación de la procedencia extra-terrestre}

En el primer tratado sobre meteoritos que se publicó en España, cercana ya la mitad del siglo XIX, Balcells ${ }^{123}$ descarta la antigua hipótesis del origen eléctrico de los meteoritos en las capas atmosféricas, con el argumento que las capas atmosféricas, lejos de tender a consolidarlos tienen por el contrario la propiedad de exfoliarlos y reducirlos a un pequeño núcleo. También descarta por inverosímil el origen volcánico terrestre, puesto que

[...] [las masas proyectadas por volcanes] se enfriarán y en su caída se presentarán no solo unas masas densas como son las aerolitas sino unas masas porosas como son todas las de origen volcánico. Las masas aerolíticas son negruzcas y vitrificadas en la sola costra esterior mientras que estas volcánicas se presentarán igualmente negruzcas en su interior. En segundo lugar [...] á semejanza de los proyectiles curvos seguirán unas trayectorias parabólicas de mayor ó menor amplitud [...] sin ninguna constancia de dirección a diferencia de las aerolitas, cuya marcha en una espiral descendente hacia el $\mathrm{O}$ hemos visto que estaba bien determinada. En tercer lugar las mismas capas admosféricas [...] seran un gran impedimento para que las masas proyectadas puedan vencer la resistencia de la admósfera, salirse fuera de ella y luego volver a comparecer en otro punto distante como si ya se hubiesen hecho independientes de la gravedad terrestre.

121 Aerolitos, mss. anónimo de 23 p en $4 .^{\circ}$; archivo de la Real Academia de Ciencias y Artes de Barcelona.

122 A. LiBEs, «De las aerolitas o piedras caídas del cielo».

123 Joaquim Balcells i Pascual [1808-1879], catedrático de física en Cervera (1829) y en la escuela de Ingenieros Industriales de Barcelona y académico de la de Ciencias. Según Maffei y Rúa, Balcells reproduce en su obra el catálogo de Chladni de 1819 (Annales de Phisique, de Chimie 31, pág. 253); pero cita muy pocos de los caídos en España. J. BALCELLS, Lithologia meteorica. 
Según el autor, las hipótesis lunar y fragmentaria habían cedido el paso años atrás a una teoría general que busca aún más lejos el origen de los aerolitos, junto con el de bólidos y asteroides, con el consenso de los principales astrónomos. Esta teoría, que denomina cósmica y a la que concede visos de probabilidad, presentada por Biot ante la Academia francesa recogiendo las ideas de Olmsted sobre los asteroides para explicar sus apariciones periódicas, relacionaba las nebulosas interplanetarias con la formación de los asteroides, la aparición de bólidos y estrellas fugaces y con la caída de aerolitos sobre la superficie terrestre:

De estos grupos de materia revolutiva proyectados desde el centro planetario [la masa solar] deduce esta hipotesis la existencia de una causa permanente capaz de producir no solo las masas planetarias mayores conocidas que giran á semejanza de la tierra alrededor del sol si no que tambien otras menores que solo se hacen visibles en ciertas épocas bajo las diversas formas de bolidas, asteroides, estrellas fugaces, y hasta de aerolitas si llega á ser tal la aproximacion que la gravitacion terrestre venza á su fuerza impulsiva ${ }^{124}$.

Balcells conocía los resultados estadísticos de Culvier-Gravier recogidos en la obra de Saygey sobre bólidos y estrellas fugaces, según los cuales es mayor la probabilidad de aparición durante los meses de agosto y noviembre, y son más frecuentes las que parten del $\mathrm{E}$ que las que vienen del $\mathrm{O}$; en su opinión las caídas de meteoritos observadas recientemente parecían corroborar tales resultados. Una vez sentado el origen extra-terrestre de los aerolitos, y sus características comunes (gran velocidad, su dirección oblicua de $\mathrm{E}$ a $\mathrm{O}$, costra negruzca vitrificada, composición química heterogénea) admite que pueden tener distintos orígenes:

$1 .^{\circ}$ de proyecciones volcánicas lunares, cuya opinion goza de mucha probabilidad entre la mayor parte de los autores por ser el satelite terrestre la gran masa mas proxima que tenemos. Pueden provenir en $2 .^{\circ}$ lugar de restos fragmentarios de alguna de las grandes masas que han desaparecido en el sistema planetario, y tambien pueden ser causadas por la concrecion de la materia revolutiva ó zodiacal que se concibe va emanando del Sol desde el principio de la creacion de la misma manera como lo concebia Anaxagoras y otros físicos de la antigüedad, pero con la diferencia que ellos concebian esta causa como única y exclusiva mientras que nosotros en la actualidad vista la diferencia de la naturaleza de unas aerolitas res-

124 J. BALCELLS, Lithologia meteorica, págs. 89-90. 
pecto á otras consideramos muy posible y aun probable que las unas provengan de los volcanes lunares las otras proceden de los restos fragmentarios y que otra gran parte sea producida por la concrecion de la materia revolutiva ó zodiacal ${ }^{125}$.

A pesar de ello, todavía en 1856 había quien insistía en el origen a partir de la condensación de vapores metálicos existentes en la atmósfera ${ }^{126}$.

\section{Conclusiones}

1. A lo largo del siglo XVIII, y muy especialmente durante su segunda mitad, se registraron en la Península Ibérica numerosos casos de observaciones, más o menos verosímiles, de fenómenos meteoríticos. Algunas de ellas habían sido ya catalogadas como tales, singularmente aquellas de las que se pudo recuperar el material caído (Terrassa, Sigena, Tasquinha). De un total de 33 casos estudiados, descartando las noticias inverosímiles o dudosas, se obtiene un catálogo en el que figuran, además de las tres caídas bien conocidas, diez bólidos observados en distintos puntos.

2. La dispersión territorial de los casos de partida dista de ser homogénea, puesto que algunas zonas han sido mejor estudiadas, mientras que de otras no se tienen apenas datos. Ello se traduce como es lógico en la distribución de los casos inventariados; si bien no en la misma proporción.

3. La distribución temporal de los datos muestra tres máximos de actividad observados: uno en la primera década del siglo, atribuible a la influencia de la caída de Terrassa; otro en la década de los cincuenta y un tercero en las dos décadas finiseculares; éstos parecen coincidir con lo observado a nivel global.

4. Los tres meteoritos recogidos a lo largo del siglo pesaron, por lo menos — el peso del de Terrasa se desconoce en realidad_-, entre 2 y $5 \mathrm{~kg}$. De ellos, tan sólo uno (Sigena) ha sobrevivido: en el Museo Nacional de Ciencias Naturales de Madrid se conserva un fragmento de $1,66 \mathrm{~kg}$ y existen varias muestras en otros museos con un peso de unos $0,52 \mathrm{~kg}$; el peso de la masa caída se estima en unos 3,5 kg. Los demás (Terrassa y Tasquinha) desaparecieron poco después de la caída.

5. Con el transcurso del tiempo evoluciona la percepción de tales fenómenos entre los autores peninsulares, desde el carácter de aviso divino que algunos

125 J. BalCELls, Lithologia meteorica, págs. 97-98.

126 E. Tuñón y QuiRós, Teoría sobre la causa de la gravedad, comprobada por fenómenos físicos, astronómicos y geológicos, Granada, Benavides, 1856, 88 págs. (cita extraída de MAFFEI \& RúA, Bibliografía mine$\mathrm{ral})$. 
asociaron con el meteorito de Terrassa a principios de siglo a las especulaciones sobre causas químico-atmosféricas, eléctricas o volcánicas, sin poner nunca en duda su procedencia terrestre. Si bien Chladni publicó su acertada hipótesis en 1794, sus escritos no llegaron a la Península más que a través de comentarios de autores franceses, en general, poco receptivos a ella; todavía en 1828 eran denostados en la traducción española de la Física de Libes. La asunción de la procedencia extra-terrestre de los meteoritos no se produjo hasta mediados del XIX. 